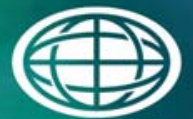

Savannah River

National Laboratory ${ }^{\mathrm{m}}$

OPERATED BY SAVANNAH RIVER NUCLEAR SOLUTIONS

\title{
Potential Application of Radionuclide Scaling Factors to High Level Waste Characterization
}

S. H. Reboul

September 2013

SRNL-STI-2013-00492 
SRNL-STI-2013-00492

Revision 0

\section{DISCLAIMER}

This work was prepared under an agreement with and funded by the U.S. Government. Neither the U.S. Government or its employees, nor any of its contractors, subcontractors or their employees, makes any express or implied:

1. warranty or assumes any legal liability for the accuracy, completeness, or for the use or results of such use of any information, product, or process disclosed; or

2. representation that such use or results of such use would not infringe privately owned rights; or

3. endorsement or recommendation of any specifically identified commercial product, process, or service.

Any views and opinions of authors expressed in this work do not necessarily state or reflect those of the United States Government, or its contractors, or subcontractors.

\section{Printed in the United States of America \\ Prepared for U.S. Department of Energy}


Keywords: Radionuclides, Scaling

Factors, High Level Waste,

Characterization

Retention: Permanent

\section{Potential Application of Radionuclide Scaling Factors to High Level Waste Characterization}

S. H. Reboul

September 2013

Prepared for the U.S. Department of Energy under contract number DE-AC09-08SR22470. 


\section{REVIEWS AND APPROVALS}

\section{AUTHOR:}

S. H. Reboul, Advanced Characterization and Processing

Date

TECHNICAL REVIEW:

M. S. Hay, Advanced Characterization and Processing

Date

R. S. Lee, Material Characterization and Nuclear Measurements

Date

\section{APPROVAL:}

C. C. Herman, SRNL Hanford Program Manager

Date

Environmental \& Chemical Process Technology Research Programs

S. L. Marra, Manager

Date

Environmental \& Chemical Process Technology Research Programs 
SRNL-STI-2013-00492

Revision 0

\section{ACKNOWLEDGEMENT}

Funding for this report was provided by the Department of Energy - Office of River Protection under Inter-Entity Work Order (IEWO) M0SRV00091. 


\section{EXECUTIVE SUMMARY}

Production sources, radiological properties, relative solubilities in waste, and laboratory analysis techniques for the forty-five radionuclides identified in Hanford's Waste Treatment and Immobilization Plant (WTP) Feed Acceptance Data Quality Objectives (DQO) document are addressed in this report. Based on Savannah River Site (SRS) experience and waste characteristics, thirteen of the radionuclides are judged to be candidates for potential scaling in High Level Waste (HLW) based on the concentrations of other radionuclides as determined through laboratory measurements. The thirteen radionuclides conducive to potential scaling are: Ni-59, Zr-93, Nb-93m, Cd-113m, Sn-121m, Sn-126, Cs-135, Sm-151, Ra-226, Ra-228, Ac-227, Pa-231, and Th-229.

The ability to scale radionuclides is useful from two primary perspectives: 1) it provides a means of checking the radionuclide concentrations that have been determined by laboratory analysis; and 2) it provides a means of estimating radionuclide concentrations in the absence of a laboratory analysis technique or when a complex laboratory analysis technique fails.

Along with the rationale for identifying and applying the potential scaling factors, this report also provides examples of using the scaling factors to estimate concentrations of radionuclides in current SRS waste and into the future. Also included in the report are examples of independent laboratory analysis techniques that can be used to check results of key radionuclide analyses.

Effective utilization of radionuclide scaling factors requires understanding of the applicable production sources and the chemistry of the waste. As such, the potential scaling approaches identified in this report should be assessed from the perspective of the Hanford waste before reaching a decision regarding WTP applicability. 


\section{TABLE OF CONTENTS}

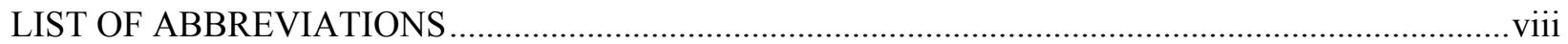

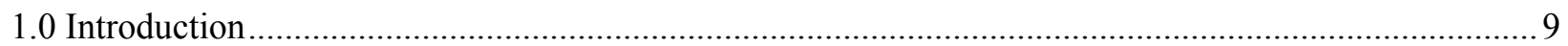

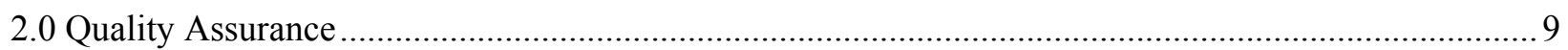

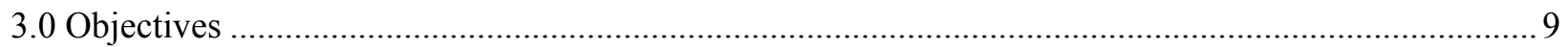

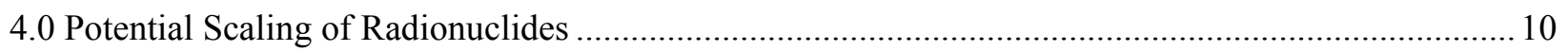

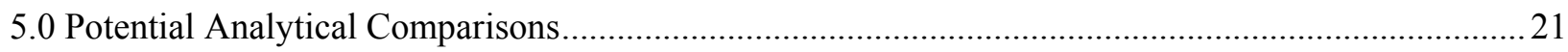

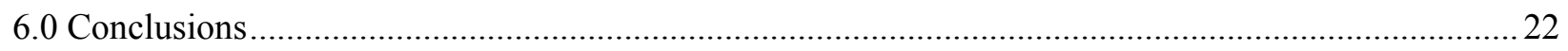

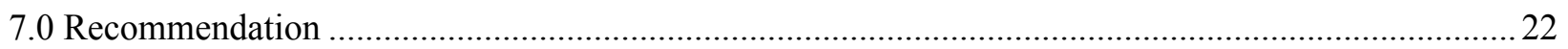

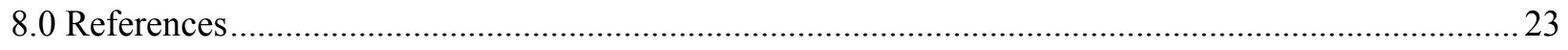

Appendix A : The Ni-59/Ni-63 Concentration Ratio..............................................................26

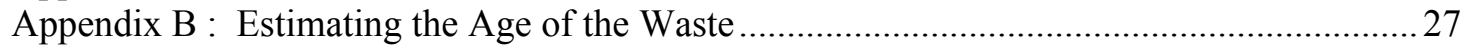

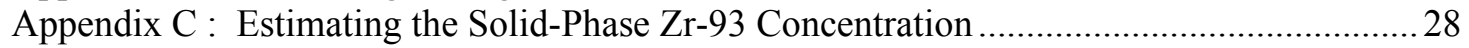

Appendix D : Estimating the Solid-Phase Nb-93m Concentration........................................29

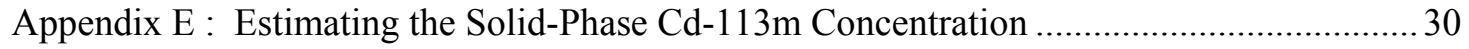

Appendix F : Estimating the Solid Phase Sn-121m Concentration .......................................... 31

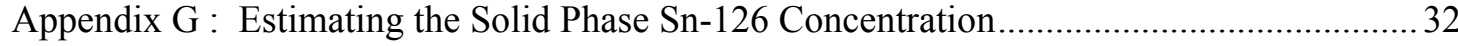

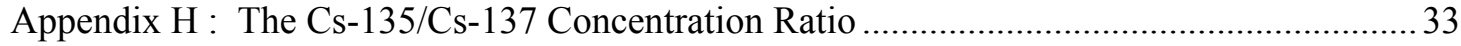

Appendix I : Estimating the Solid Phase Sm-151 Concentration ............................................ 34

Appendix J : Estimating the Solid Phase Ra-226 Concentration..............................................35

Appendix K : Estimating the Solid Phase Ra-228 Concentration .......................................... 36

Appendix L : Estimating the Solid Phase Ac-227 and Pa-231 Concentrations ........................ 37

Appendix M : Estimating the Solid Phase Th-229 Concentration........................................... 38 


\section{LIST OF ABBREVIATIONS}

$\begin{array}{ll}\text { AM } & \text { Atomic mass } \\ \text { DOE } & \text { Department of Energy } \\ \text { DQO } & \text { Data quality objective } \\ \text { DWPF } & \text { Defense Waste Processing Facility } \\ \text { FY } & \text { Fission yield } \\ \text { FYSF } & \text { Fission yield scaling factor } \\ \text { HLW } & \text { High level waste } \\ \text { ICP-AES } & \text { Inductively coupled plasma - atomic emission spectroscopy } \\ \text { ICP-MS } & \text { Inductively coupled plasma - mass spectrometry } \\ \text { LEPS } & \text { Low energy photon spectroscopy } \\ \text { MDC } & \text { Minimum detectable concentration } \\ \text { MDL } & \text { Minimum detection limit } \\ \text { SB } & \text { Sludge batch } \\ \text { SRNL } & \text { Savannah River National Laboratory } \\ \text { SRS } & \text { Savannah River Site } \\ \text { WTP } & \text { Waste Treatment and Immobilization Plant } \\ \text { DQO } & \text { Data quality objective }\end{array}$




\subsection{Introduction}

Understanding of the concentrations and distribution of radionuclides in High Level Waste (HLW) is required when making decisions regarding waste storage and disposition. While sampling and analysis provides the primary means for characterizing radionuclides in HLW, non-laboratory characterization methods are important from the perspective of demonstrating analytical results are consistent with expectations, and for estimating radionuclide concentrations when a laboratory analysis technique is not available or when a laboratory analysis technique is ineffective.

Use of scaling factors offers a potential means of estimating radionuclide concentrations in HLW based on process knowledge, radiological properties, solubility characteristics, and waste chemistry. Potential scaling factors are not available for all radionuclides, only those that meet criteria assuring consistency of radionuclide production, processing, and waste chemistry.

As preparations are made to start-up Hanford's Waste Treatment and Immobilization Plant (WTP), potential use of scaling factors for characterizing the WTP waste is worthy of consideration. Per the Data Quality Objectives (DQOs) of WTP's Feed Acceptance Criteria, ${ }^{1}$ a total of forty-five radionuclides will require characterization for determining feed acceptability. Although laboratory analyses will be required for the majority of radionuclides, the preferred method of quantifying some of the radionuclides may be by scaling.

In this report, a summary of the primary sources, characteristics, and behaviors of the WTP DQO radionuclides will be provided, along with a discussion of the rationale as to whether or not each radionuclide is a candidate for potential scaling. These discussions will be based on the experience gained through characterization of the Savannah River Site (SRS) HLW sludge batches processed through the Defense Waste Processing Facility (DWPF), and through characterization performed in support of other HLW processing activities. In cases where scaling factors are applicable, the scaling methodologies will be explained and supplemented with examples of the scaling calculations for current and future radionuclide concentrations. Examples of simple analytical comparison methods for checking key radionuclide results will also be provided.

\subsection{Quality Assurance}

This report was developed in accordance with the protocols identified in Task Technical and Quality Assurance Plan SRNL-RP-2013-00310. ${ }^{2}$

Requirements for performing reviews of technical reports and the extent of review are established in manual E7 2.60. SRNL documents the extent and type of review using the SRNL Technical Report Design Checklist contained in WSRC-IM-2002-00011, Rev. $2 .^{3}$

\subsection{Objectives}

1) To address each of the WTP DQO radionuclides, utilizing SRS HLW process knowledge and experience, to determine potential scalability;

2) As applicable, to provide calculation methodologies and example calculations for estimating concentrations of radionuclides in SRS HLW via scaling; and 
3) To provide examples of independent laboratory analysis techniques that can be used to judge results of other radionuclide analysis techniques.

\subsection{Potential Scaling of Radionuclides}

For radionuclide scaling factors to be effective, there must be a technical basis that ensures consistency with respect to production, removal, and chemistry. A discussion of these characteristics is given below for each of the WTP DQO radionuclides. Based on the characteristics, each discussion contains a conclusion regarding whether or not the radionuclide is amenable to potential scaling. If potential scaling is appropriate, the methodology for doing so is presented, and example calculations utilizing the methodology are presented. Note that the example calculations have been placed in Appendices, for ease of access.

The radiological and solubility information below came from a relatively small number of references. The dominant production mechanisms were identified in the Radiological Health Handbook. ${ }^{4}$ The radionuclide half-lives, neutron absorption cross sections, and fission yields were most often those identified in the Chart of the Nuclides. ${ }^{5}$ In cases where an alternate reference was utilized, the reference was specifically cited. The relative radionuclide solubilities and distributions were taken from a series of references: reports addressing characterization of DWPF sludge batches, ${ }^{6-13}$ reports addressing characterization of Tank Farm saltcake and supernatant, ${ }^{14-16}$ and miscellaneous reports focusing on concentrations and distributions of specific radionuclides. ${ }^{17-19}$

Since the primary sources of fission products in SRS waste are from fission of U-235 used to generate neutrons and fission of U-235 in uranium irradiated to generate $\mathrm{Pu}-239$, all of the fission yields identified in this report are those applicable to U-235, as opposed to those applicable to U-233 or Pu-239. (With few exceptions, the majority of Hanford fission products have also been generated through fission of U235). It must be understood that when fission of $\mathrm{U}-233$ or Pu-239 is the source of the fission products, the applicable fission yields will be those pertaining to U-233 or Pu-239.

When assessing the possibility of utilizing scaling, it is assumed that processing has not changed the distribution of radionuclides from that in the original waste. In other words, no waste radionuclides have been selectively concentrated, removed, and/or redistributed through supplemental chemical recovery and/or operational processes. If such processes have been performed, the scaling assumptions may no longer be valid, and correspondingly, the application of scaling factors may no longer be appropriate. For this reason, scaling is rarely conducive to characterizing liquid-phase radionuclides, due to the propensity for changing the liquid-phase elemental distributions through supernatant transfers, mixing, and/or evaporation processes. An exception applies to isotopes of the same element, which have identical chemical behavior and therefore have the potential to migrate in solution together, given that conditions support such behavior. Because of the differences between SRS and Hanford waste types, processing, and blending, the scaling factors developed for SRS waste may not necessarily be applicable to Hanford waste.

H-3: The primary source of H-3 in HLW is from ternary fission that occurred during irradiation of the uranium fuel and targets, resulting in the presence of supernatant phase tritiated water. Larger quantities of $\mathrm{H}-3$ were produced through the $\mathrm{Li}^{6}(\mathrm{n}, \alpha)$ reaction, with the specific objective of creating $\mathrm{H}-3$ product, but waste from that production process was typically dispositioned outside of the HLW arena. ${ }^{20} \mathrm{H}-3$ was also generated through neutron absorption interactions in the heavy water moderator reactors. The halflife of H-3 is relatively short, $\sim 12$ years. Analysis of H-3 in tritiated water is relatively simple. Distillation of the liquid phase material carries tritiated water into the condensate, effectively separating the H-3 from the non-volatile radionuclides left behind. Liquid scintillation counting of the condensate is 
the most common means of measuring H-3. However, if high analytical sensitivity is needed, internal gas proportional counting is also available, albeit more complex. Because of the short half-life, the range of potential sources, and the high mobility of the tritiated water form, a simple means of scaling of tritium is not available. However, given that the tritiated water is volatilized during glass production (due to the high melter temperatures), it is assumed that the tritium content of the final wasteform is negligible.

C-14: The primary sources of $\mathrm{C}-14$ are from the $\mathrm{N}^{14}(\mathrm{n}, \mathrm{p})$ and $\mathrm{O}^{17}(\mathrm{n}, \alpha)$ reactions that occurred within the aluminum cladding of the irradiated fuels and targets. When the cladding was dissolved in caustic, the C14 was retained in the waste in the form of carbonate, with much of the carbonate partitioned to the liquid phase (as free carbonate) and therefore captured in salt. ${ }^{21}$ In contrast, when the cladding was dissolved in acid, the C-14 was volatilized in the form of carbon dioxide gas and thus, not retained in waste stream. The half-life of C-14 is relatively long, 5700 years. Analysis of C-14 can be challenging, as it involves conversion of carbonate to gaseous carbon dioxide and subsequent capture prior to measurement. Because the quantity of $\mathrm{C}-14$ that is retained in the waste is a function of the cladding dissolution process and since most of C-14 partitions to the liquid phase, a simple means of scaling C-14 is not available. However, given that all of the carbon in the waste is converted to gaseous oxides which are volatilized during glass production, it is assumed that the $\mathrm{C}-14$ content of the final wasteform is negligible. ${ }^{22}$

Co-60: The primary source of Co-60 is from the $\mathrm{Co}^{59}(\mathrm{n}, \gamma)$ reaction that occurred during irradiation of the fuel and targets. In the alkaline waste stream, the cobalt is assumed to exist as a hydroxide (or oxyhydroxide or oxide) which is very insoluble and thus, primarily associated with the solid phase (as a precipitated solid). The half-life of Co-60 is relatively short, $\sim 5$ years. Because Co-60 emits two characteristic gamma rays $(1.173$ and $1.332 \mathrm{MeV})$, it is relatively straightforward to quantify using high resolution gamma spectrometry. Given the ease of measurement and the very short half-life, a simple means of scaling is not available.

Ni-59 and Ni-63: The primary sources of Ni-59 and $\mathrm{Ni}-63$ are from the $\mathrm{Ni}^{58}(\mathrm{n}, \gamma)$ and $\mathrm{Ni}^{62}(\mathrm{n}, \gamma)$ reactions (respectively) that occurred during irradiation of the fuel and targets. Like cobalt, in the alkaline waste stream, the nickel is assumed to exist as a hydroxide (or oxyhydroxide or oxide) which is very insoluble and thus, primarily associated with the solid phase (as a precipitated solid). The half-lives of the Ni-59 and Ni-63 are 76,000 and 101 years, respectively. As such, over the next several thousands of years, the activity of the Ni-59 will drop only slightly, while the activity of the Ni-63 will quickly approach zero. Because the chemistries of the two isotopes are identical, they will partition identically, and thus maintain a constant Ni-59:Ni-63 ratio in the solid and liquid phases of waste at any given point in time. Although the Ni-63 half-life is relatively short on a geological basis, it is still long enough on an operations basis that expectations regarding Ni-59:Ni-63 ratios will be meaningful and useful. Laboratory analysis of the two isotopes requires application of nickel purification steps, followed by multiple measurement techniques, and yield adjustment. Ni-59 is measured using Low Energy Photon Spectroscopy (LEPS), Ni-63 is measured using liquid scintillation counting, and the elemental nickel yield is measured using inductively couple plasma - atomic emission spectroscopy (ICP-AES). Because of the relative complexity of the method, comparison of the laboratory results and the expected isotope ratio is certainly warranted, as it provides a quick basis for gauging the quality of the data. For fresh SRS waste, the expected Ni-59:Ni-63 activity ratio is about $0.010 .^{23,24}$ Adjusting for decay, the expected activity ratio for 60 year old waste is about 0.015 . Given the expected range of sampling and analysis uncertainties $( \pm 20 \%)$ and propagating the uncertainties of the numerator and denominator, it is not unreasonable to expect that current analytical results would identify Ni-59:Ni-63 activity ratios falling in the 0.007 to 0.019 range, with those at the lower end for newer waste and those at the upper end for older waste. With rare exception, this expectation is borne out by the characterization data of the completed sludge batches. An alternative use of the ratio is to estimate concentrations of Ni-59 based on Ni-63 concentrations. This is particularly useful for liquid phase characterization, when the Ni-59 concentration is below the minimum detectable concentration (MDC), and the MDC of the Ni-59 is high relative to the measured Ni- 
63 concentration, due to the relatively low counting efficiency of LEPS. This provides a means for lowering the upper limit of the reported Ni-59 concentration. In such cases, it is probably appropriate to apply a ratio at the upper end of the range, for conservatism. See Appendix A for examples of applications.

Se-79: Se-79 is a fission product, with a $0.045 \%$ fission yield and $2.9 \mathrm{E}+05$ year half-life. Despite the low fission yield, the relative quantity of Se-79 persisting into the future can be significant, due to the long half-life. The chemical behavior of selenium is different from that of many of the other waste constituents, specifically with respect to reactivity, solubility, and volatility. HLW characterization data at SRS suggest that a portion of the Se-79 is separated during canyon processing from the bulk waste stream received into the Tank Farm. Such separation is attributed to volatilization reactions, extraction inefficiencies, and/or other process impacts. For these reasons, the quantity of Se-79 in a typical batch of waste can fluctuate significantly. As such, a simple means of scaling Se-79 is not available. Because of selenium's unusual chemistry, laboratory analysis of Se-79 can be challenging. The analytical method employed at SRNL utilizes multiple chemical separation processes to purify the selenium, beta counting to measure the Se-79, and neutron activation analysis to determine the selenium yield.

Sr-90/Y-90: Over the first few hundred years of the HLW's life, Sr-90 and its short-lived daughter Y-90 are the primary contributors of the solid-phase activity. Typically present in the form of strontium carbonate, the vast majority of the strontium (99+\% of the strontium) is insoluble in the high $\mathrm{pH}$ waste, with a very minor soluble fraction $(<1 \%)$. The source of the Sr-90 is fission, with a $5.8 \%$ fission yield and a 28.8 year half-life. Because of Sr-90's high initial activity, high solid-phase partitioning, and moderately short half-life, knowledge of the current Sr-90 concentration provides an effective basis for estimating the age of the waste. Laboratory analysis of Sr-90 is not simple, but has been honed over time to maximize practicality. The general approach is to purify the strontium via chemical separation, measure the Sr-90 by beta counting, and adjust the results for the yield. Comparison of the measured Sr90 concentrations with those of the fresh waste as determined by fission yield scaling factors offers a relatively simple means of estimating the waste age (see Appendix B for details of the age determination). The age of the waste is important from two perspectives: 1) it provides a basis for comparison with expectations - if the measured age is consistent with expectations, there is confidence that the analysis was performed effectively; and 2) it provides a basis for utilizing scaling factors that require back-decay corrections.

Zr-93: Zr-93 is a fission product, with a $6.35 \%$ fission yield and a $1.5 \mathrm{E}+06$ year half-life. Some portion of the $\mathrm{Zr}-93$ that is produced is transmuted to $\mathrm{Zr}-94$, through neutron absorption. However, given that the thermal neutron cross section is small $\left(\sigma_{\gamma} \sim 1,15\right)$, it is assumed that the portion of $\mathrm{Zr}-93$ that is transmuted is small. (In the notation above, the thermal neutron capture cross section is approximately one Barn, and the resonance integral is fifteen). Zirconium is very insoluble in alkaline waste and therefore highly partitioned to the solid phase (likely in the form of an oxyhydroxide). As such, it is a radionuclide that lends itself to effective scaling based on application of a fission yield scaling factor derived from other insoluble fission products. Because of its long half-life, year to year quantities of $\mathrm{Zr}$ 93 in waste need not be adjusted for decay. Laboratory analysis of Zr-93 is not simple, as it requires an aggressive dissolution approach, purification via chemical separation, subsequent measurement, and recovery adjustment. Inductively coupled plasma mass spectroscopy (ICP-MS) is the Zr-93 measurement technique currently utilized at SRS. See Appendix C for details of the Zr-93 scaling methodology.

Nb-93m: $\mathrm{Nb}-93 \mathrm{~m}$ is the relatively short-lived daughter of $\mathrm{Zr}-93$. Its half-life is 16.1 years, and as such, its accumulation from decay of Zr-93 occurs over a relatively short period into the future (over a period of about 150 years). However, because of the long half-life of $\mathrm{Zr}-93$ (1.5E+06 years), the accumulated Nb$93 \mathrm{~m}$ persists for hundreds of thousands of years. Laboratory analyses of $\mathrm{Nb}-93 \mathrm{~m}$ are performed using chemical separations to purify niobium, followed by ICP-MS measurements. Like zirconium, niobium is 
very insoluble in alkaline waste and therefore highly partitioned to the solid phase (likely as an oxide). As such, the concentration of Nb-93m in HLW sludge is effectively scaled based upon the Zr-93 concentration and the age of the waste.

As Zr-93 decays, approximately $97 \%$ of the transformations result in the production of $\mathrm{Nb}-93 \mathrm{~m}$ atoms. Since the half-life of Nb-93m is significantly shorter than that of $\mathrm{Zr}-93$ (1.5E+06 years), the in-growth of the $\mathrm{Nb}-93 \mathrm{~m}$ follows that of the standard curve for a daughter approaching secular equilibrium with a parent radionuclide. As a function of time, the $\mathrm{Nb}-93 \mathrm{~m}$ activity is given by the following relationship:

$\mathrm{A}_{\mathrm{Nb}-93 \mathrm{~m}}(\mathrm{t})=0.97 * \mathrm{~A}_{\mathrm{Zr}-93, \mathrm{t}=0} * \exp (-0.693 \mathrm{t} / 1.5 \mathrm{E}+06) *[1-\exp (-0.693 \mathrm{t} / 16.1)]$

where $\mathrm{A}_{\mathrm{Zr}-93, \mathrm{t}=0}$ is the $\mathrm{Zr}-93$ activity at time zero (equivalent to the current activity, due to the long half of $\mathrm{Zr}-93)$, and $\mathbf{t}$ is the age of the waste in years.

Utilization of the in-growth relationship above provides a simple means of calculating the Nb-93m activity based on the Zr-93 activity and the age of the waste (see Appendix D for details of the calculation). As discussed above, the Zr-93 concentration is either determined by laboratory analysis or it is estimated based on the fission yield scaling factor.

Tc-99: Tc-99 is a fission product, with a $6.1 \%$ fission yield and a $2.1 \mathrm{E}+05$ year half-life. The solubility of technetium is a function of oxidation state, with reduced technetium being very insoluble and oxidized technetium being very soluble at high $\mathrm{pH}$. In SRS waste, the majority of technetium is typically soluble as a pertechnetate anion and therefore dominant in salt streams. ${ }^{25,26}$ Still, the minor portions of Tc-99 that are associated with insoluble solids (likely in the form of hydrated technetium dioxide) are almost always present at detectable concentrations. In Hanford waste, the presence of chelation agents may increase the fraction of technetium partitioning to the liquid phase. Laboratory analyses of Tc-99 are typically performed utilizing ICP-MS measurements and/or chemical separations coupled with beta counting, depending on the sensitivity requirements. In cases where natural ruthenium is present, chemical purification will be required prior to ICP-MS measurements, due to the presence of Ru-99, which would augment the mass 99 ICP-MS signal. Because of the high expected solubility/mobility, a simple means of scaling technetium is not available.

Ru-106: $\mathrm{Ru}-106$ is a fission product, with a $0.402 \%$ fission yield and a 1.02 year half-life. Ruthenium is very insoluble in alkaline waste and therefore highly partitioned to the solid phase, likely in the form of a metal hydroxide and/or oxide. Laboratory analyses of $\mathrm{Ru}-106$ are routine, utilizing a cesium removal step to increase sensitivity followed by measurement via high resolution gamma spectroscopy. Due to the very short half-life, scaling of Ru-106 is not recommended. This is primarily because minor differences in the age of the waste have a tremendous impact on the fraction of Ru-106 that remains. As such, scaling of Ru-106 would require extremely accurate knowledge of the age of the waste, which is highly unlikely. In addition, for all but fresh waste, the fraction of original Ru-106 that remains will be very small or insignificant, due to the short half-life.

Cd-113m: Cd- $113 \mathrm{~m}$ is a fission product, with an extremely low fission yield (1.66E-04\%) ${ }^{27}$ and a 14.1 year half-life. Cd-113m has a very large thermal neutron absorption cross section $\left(\sigma_{\gamma} \sim 20600,390\right)$, so what little of it is produced through fission is transmuted by burn-up. Cadmium is very insoluble in alkaline waste and therefore highly partitioned to the solid phase, likely in the form of a metal hydroxide and/or oxide. Scaling based on relative fission yield is the primary practical option for quantifying Cd$113 \mathrm{~m}$. (Note that laboratory analysis of Cd-113m is not currently performed at SRNL). Depending on the level of understanding of the applicable burn-up rate, either a very conservative upper bounding value for the Cd-113m concentration can be computed or a "best" estimate of the Cd-113m concentration can computed. For a conservative upper bounding value, the Cd-113m concentration in fresh waste (at time 
zero) is calculated using the applicable fission yield scaling factor, and then the value is adjusted for decay, based on the age of the waste. If the burn-up factor is known, the "best" estimate is determined by reducing the upper bounding value per the burn-up rate. See Appendix E for details of the calculations.

Sn-121m: Sn- $121 \mathrm{~m}$ is a fission product, with very low fission yield $(0.0007 \%)^{28}$ and 44 year half-life. In addition to being a fission product, it also is produced by the $\operatorname{Sn}^{120}(\mathrm{n}, \gamma)$ activation reaction. As such, scaling of Sn-121m based on relative fission yield alone would be inadequate. Available data suggest that on average about $20 \%$ of the tin in SRS HLW is soluble, while the remainder is insoluble and therefore partitioned to the solid phase, likely in the form of a hydrated oxide. Laboratory analyses of Sn- $121 \mathrm{~m}$ are routine, using chemical separation to remove cesium (to increase sensitivity), followed by LEPS measurements. Unfortunately, because of the copious amounts of other low energy photon emitters in HLW, the quantities of Sn-121m in sludge are often undetectable (below the minimum detection limits). An alternative to direct measurement in sludge is application of an Sn-121m:Sn-126 ratio determined for the waste supernatant. Because of the relative low solubilities of most of the interfering radionuclides, detection of the tin radionuclides in the supernatant phase is often more effective than detection of the same radionuclides in sludge. Assuming the supernatant phase Sn-121m:Sn-126 ratio can be determined through direct measurements, the ratio can be applied to the solid phase Sn-126 concentration to project the solid phase Sn-121m content. Note that the solid phase Sn-126 concentration can either be determined by direct measurement or by scaling, as described below. See Appendix F for details of determining the Sn-121m:Sn-126 ratio and using it to project the concentration of solid phase Sn-121m.

Sn-126: Sn-126 is a fission product, with low fission yield (0.059\%) and long half-life (2.3E+05 years). As identified in the Sn-121m discussion above, available data suggest that about $20 \%$ of the tin in SRS HLW is partitioned to the liquid phase, and the remainder is partitioned to the solid phase. ${ }^{26,29}$ Although the soluble fraction is not insignificant, it is still a minor portion of the tin. As such, use of a scaling factor to estimate of the solid phase Sn-126 based on the fission yield scaling factor is appropriate, with the understanding that the estimated Sn-126 concentration will be somewhat high. Laboratory analysis of Sn-126 is routinely performed using chemical separation to remove cesium (to increase sensitivity), followed by high resolution gamma spectroscopy. Unfortunately, using this analytical method, the concentrations of Sn-126 are typically undetectable (below the minimum detection limits). Consequently, the scaled Sn-126 values may be preferred, as they are usually significantly lower than the minimum detection limits of the analytical technique, yet still conservative. See Appendix G for details of the Sn126 scaling calculation.

Sb-125: The primary source of $\mathrm{Sb}-125$ is beta decay of $\mathrm{Sn}-125$ produced through the $\operatorname{Sn}^{124}(\mathrm{n}, \gamma)$ activation reaction. The half-life of Sb-125 is short, 2.76 years. Because the half-life of the parent radionuclide (Sn125 ) is so extremely short (9.6 days), the parent radionuclide is no longer present today, and all remaining $\mathrm{Sb}-125$ is due to in-growth from Sn-125 that occurred either during the irradiation period or shortly thereafter. This is different from the case of daughters growing-in from long-lived radionuclides, where daughter activities can continue to accumulate into the future. In alkaline waste, antimony is thought to exist in the form of an oxide or hydrated sodium oxide, with the potential for significant solubility. Laboratory analysis of Sb-125 is routinely performed using chemical separation to remove cesium (to increase sensitivity), followed by high resolution gamma spectroscopy. Given the very short half-life (2.76 years) and the potentially high solubility/mobility, a simple scaling factor for Sb-125 is not available.

I-129: Iodine-129 is a fission product, with a $0.54 \%$ fission yield and a $1.57 \mathrm{E}+07$ year half-life. Some part of the I-129 that is produced is transmuted to I-130, through neutron absorption. However, given that the thermal neutron cross section is small $\left[\sigma_{\gamma}(20+10), 50\right]$, it is assumed that the portion of I-129 that is transmuted is modest. A portion of the iodine may also be separated from the waste stream via volatilization during dissolution. At SRS, gaseous $\mathrm{I}_{2}$ generated during dissolution is captured on silver 
nitrate coated Berl saddles, which are subsequently dispositioned through an alternate route. The net result is that only a portion of the total I-129 makes its way into the HLW stream. In alkaline waste, the vast majority of iodine is expected to be in the form of soluble iodide anion. ${ }^{30,31}$ As such, the portion that is insoluble and thus partitioned to the solid phase is minimal. Laboratory analysis of I-129 is performed using multi-step chemical separations to purify the iodine, LEPS counting to measure the I-129, and neutron activation analysis to determine the iodine yield. Because of the iodine removal performed during dissolution and the high solubility/mobility of the iodine in liquid waste, a simple means of scaling I-129 is not available.

Cs-134: The primary source of Cs-134 is the $\mathrm{Cs}^{133}(\mathrm{n}, \gamma)$ activation reaction. A lesser source of Cs-134 is fission, given the very minor fission yield (7.7E-06\%). ${ }^{28}$ The half-life of Cs-134 is short, 2.1 years. A portion of the Cs-134 is transmuted to Cs-135 through neutron absorption. However, given that thermal neutron cross section of Cs-134 is moderately low $\left(\sigma_{\gamma} 140,60\right)$, the portion of the Cs-134 that is transmuted is expected to be limited. In alkaline waste, the majority of cesium is expected to be in the form of soluble nitrate, nitrite, and hydroxide salts. As such, the portion that is insoluble and thus partitioned to the solid phase is minor. Laboratory analysis of Cs-134 is performed using high resolution gamma spectroscopy. Since the ratios of cesium isotopes in the liquid and solid phases of a given waste should be equivalent to one another (due to all the cesium isotopes being chemically identical), there is the potential for scaling quantities of one cesium isotope based on the quantities of the other cesium isotopes, in either phase of the waste. However, in the case of Cs-134, scaling is not recommended, due to its short half-life.

Cs-135: Cs-135 is the daughter of the very short-lived fission product Xe-135 (the fission yield and halflife of Xe-135 are $6.54 \%$ and 9.1 hours, respectively). As described above, a limited amount of Cs-135 is also produced through neutron activation of Cs-134. In addition, a small portion of the Cs-135 is transmuted to Cs-136, as indicated by the minor thermal neutron cross section $\left(\sigma_{\gamma} \sim 8.7,90\right)$. Because the half-life of Cs-135 is long ( $2.3 \mathrm{E}+06$ years), it is the one cesium radioisotope that persists well into the future. Despite the high fission yield of Xe-135, the quantity of Cs-135 that is produced is relatively small, due to the high fraction of Xe-135 that is transmuted to Xe-136 before it can decay to Cs- 135 . This is a result of the very high thermal neutron cross section of Xe-135 $\left(\sigma_{\gamma} 2.6 \mathrm{E}+06, \sim 7600\right)$. Available data indicate that for the bulk of material processed at SRS, approximately $90 \%$ of the Xe-135 was transmuted prior to decay. In other words, approximately $10 \%$ of the Xe-135 decayed to produce Cs- 135 .

Knowledge of this breakdown provides a basis for scaling Cs-135 against Cs-137, assuming the age of the waste is known or can be estimated. The age of the waste is important from the perspective of understanding what fraction of the original Cs- 137 has been removed through decay. As stated above, the majority of cesium in alkaline waste is soluble and partitioned to the liquid phase, in the form of soluble nitrate, nitrite, and hydroxide salts. Since all cesium isotopes behave the same from a chemical perspective, Cs-135 scaling can be applied to both liquid and solid phases. Laboratory analysis of Cs-135 in HLW sludge is typically performed using chemical separations to purify the cesium (to remove barium), followed by ICP-MS measurements and yield adjustments. In contrast, ICP-MS measurements of Cs-135 in HLW supernatant can often be performed without the cesium purification steps, since supernatant is generally free of barium, due to the low barium solubility. See Appendix H for details of the Cs-135 scaling methodology.

Cs-137: Cs-137 is a fission product, with a $6.19 \%$ fission yield and a 30 year half-life. As stated above, the majority of cesium in alkaline waste is soluble, existing in the form of dissolved nitrate, nitrite, and hydroxide salts. Laboratory analysis of Cs-137 is routinely performed utilizing traditional gamma spectroscopy. Given the high relative activities of Cs-137 in the current day HLW samples, gamma spectroscopy provides a very effective and simple means of acquiring accurate Cs-137 data. Combining the Cs-137 data with knowledge of the age of the waste provides a technically sound basis for scaling Cs- 
135 (see Cs-135 discussion above). Scaling of Cs-137 is not recommended given its dominance in waste and relative ease of measurement.

Sm-151: The primary source of Sm-151 is through decay of the short-lived fission product Pm-151 (the fission yield and half-life of Pm-151 are $0.419 \%$ and 1.2 days, respectively). Sm-151 can also be produced through activation of Sm-150. However, this source is expected to be trivial, since so little Sm150 is expected to be present and since the thermal neutron cross section of Sm-150 is small $\left(\sigma_{\gamma} 103,300\right)$. A portion of the Pm-151 atoms produced through fission will be transmuted to Pm-152 before they can decay to Sm-151, due to neutron activation. But this portion will be small, due to the relatively low thermal neutron cross section of Pm-151 $\left(\sigma_{\gamma} \sim 200\right)$. A much more significant reduction in the quantity of $\mathrm{Sm}-151$ is associated with the transmutation of Sm-151 to Sm-152 by neutron activation. This is due to the high thermal neutron cross section of Sm-151 $\left(\sigma_{\gamma} 15200,3500\right)$. Laboratory analyses of Sm-151 are performed using chemical separations to purify the samarium, followed by liquid scintillation measurements, and yield adjustments. Available data indicate that for the bulk of nuclear material processed at SRS, approximately $70 \%$ of the Sm-151 was eliminated through transmutation. In other words, only about $30 \%$ of the total Sm-151 produced through Pm-151 decay remained at the conclusion of the irradiation period. Knowledge of this breakdown provides a basis for estimating the quantity of $\mathrm{Sm}-151$ based on the fission yield scaling factor and the age of the waste. The age of the waste is important from the perspective of understanding what fraction of the Sm-151 has been removed through decay. The half-life of Sm-151 is 90 years, a length that makes Sm-151 one of the dominant sources of radioactivity when the waste is approximately 300 years old. Like all lanthanides, samarium is very insoluble in alkaline waste and therefore highly partitioned to the solid phase, likely in the form of a metal hydroxide. The high solid-phase partitioning is a prerequisite for effectively estimating the $\mathrm{Sm}-151$ based on solid-phase fission yield scaling factor. See Appendix I for details of the Sm-151 scaling methodology.

Eu-152, 154, and 155: Eu-152, 154, and 155 are fission products, but are also produced through the $\mathrm{Eu}^{151}(\mathrm{n}, \gamma)$ activation reaction, the $\mathrm{Eu}^{153}(\mathrm{n}, \gamma)$ activation reaction, and through decay of $\mathrm{Sm}-155$ from the $\mathrm{Sm}^{154}(\mathrm{n}, \gamma)$ activation reaction, respectively. The fission yields and half-lives are $2.6 \mathrm{E}-10 \%, 1.9 \mathrm{E}-7 \%$, and $3.2 \mathrm{E}-2 \%$, and $13.5,8.6$, and 4.8 years, respectively. ${ }^{28}$ All three of these isotopes have high thermal neutron cross sections (11000, 1400, 3900 barns, respectively), so large fractions of the isotopes are transmuted to higher isotopes. Because of the relatively short half-lives, decay during the typical waste storage periods is great. Like other lanthanides, europium is very insoluble in alkaline waste and highly partitioned to the solid phase, likely in the form of hydroxides and/or oxides. Laboratory analyses of the isotopes are routine, utilizing chemical separations to remove cesium (to increase sensitivity), followed by high resolution gamma spectroscopy. Given the short relative half-lives of the isotopes and the complexity of the various production/transmutation paths, a simple means of scaling the isotopes is not available.

Ra-226: Ra-226 is the daughter of Th-230 and a descendant of U-234 and Pu-238. Its half-life is approximately 1600 years, and as such, its accumulation from the decay of parent radionuclides occurs over many thousands of years. Laboratory analysis of Ra-226 is complex, utilizing chemical separations to purify the radium, in-growth and capture of gaseous daughter Rn-222 and successive decay products leading to $\mathrm{Pb}-214$, and subsequent measurements of $\mathrm{Pb}-214$ via high purity gamma spectroscopy. As an alkaline earth metal, the form and solubility of radium in alkaline waste is very similar to that of strontium - present as an insoluble carbonate and highly partitioned to the solid phase. Because thorium, uranium, and plutonium are also very insoluble, the concentrations of Ra-226 in HLW sludge can be effectively scaled based on the age of the waste and the concentrations of Th-230, U-234, and Pu-238. In SRS waste, most of the current Th-230 content is present as an impurity that was introduced with the Thoria $\left(\mathrm{ThO}_{2}\right)$ utilized in the Thorex campaigns. Per the specification, the Th-230 concentration is assumed to be $1 \mathrm{ppm}$ of the $\mathrm{ThO}_{2}$ concentration, ${ }^{32}$ and the $\mathrm{ThO}_{2}$ concentration is determined through 
laboratory analysis of the Th-232 (by ICP-MS). Also determined through laboratory analysis are the current concentrations of U-234 (by ICP-MS) and Pu-238 (by alpha spectrometry). Since the half-life of $\mathrm{Pu}-238$ is relatively short ( 87.7 years) and $\mathrm{Pu}-238$ will ultimately be the largest source of future Ra-226, it is important to back-decay adjust the $\mathrm{Pu}-238$ concentration to that of the fresh waste (for time equal zero). This can easily be calculated based on the following relationship and knowledge of the age of the waste:

$\mathrm{A}_{\mathrm{Pu}-238, \mathrm{t}=0}=\mathrm{A}_{\mathrm{Pu}-238, \mathrm{t}=\mathrm{T}} * \exp (0.693 \mathrm{~T} / 87.7)$

where $A_{\mathrm{Pu}-238, \mathrm{t}=0}$ is the $\mathrm{Pu}-238$ activity in the fresh waste, $\mathrm{A}_{\mathrm{Pu}-238, \mathrm{t}=\mathrm{T}}$ is $\mathrm{Pu}-238$ activity at the time of the measurement, and $\mathrm{T}$ is the time in years that elapsed between when the waste was fresh and the measurement was performed.

Note that $\mathrm{T}$ can either be determined based on a calculation such as that identified for the case of Sr-90 (utilizing the fission yield scaling factor), or it can be conservatively estimated based on the history of waste receipt.

Because of the very long half-lives of Th-230 and U-234 relative to the age of the waste, back-decay calculations for the Th-230 and U-234 concentrations are not necessary. (Back-decay is only necessary for $\mathrm{Pu}-238)$.

Once the Th-230, U-234, and Pu-238 concentrations are identified, the simplest way of estimating Ra-226 at any given point in time is through use of an in-growth calculation program, such as RadCalc 4.1. (RadCalc 4.1 is a Nuclear Quality Assurance-1 validated software application that was developed to assist the Department of Energy [DOE] in performing calculations consistent with requirements and methods prescribed by the DOE, the U. S. Nuclear Regulatory Commission, the Environmental Protection Agency, and the International Commission on Radiation Protection. RadCalc 4.1 was prepared for the DOE by EnergySolutions Federal Solutions and is available for free download on the internet). The general approach is to enter the Th-230, U-234, and $\mathrm{Pu}-238$ concentrations at time zero, select a decay period, and have the program calculate the concentration of Ra-226. See Appendix J for an example of the scaling calculation.

Ra-228: Ra-228 is the relatively short-lived daughter of Th-232. The half-life of Ra-228 is 5.76 years, and as such, its accumulation from decay of Th-232 occurs over a relatively short time period (over a period of about 50 years). However, because of the extremely long half-life of Th-232 (1.4E+10 years), the accumulated Ra-228 persists for billions of years into the future. Laboratory analysis of Ra-228 is typically performed utilizing chemical separations to purify the radium, an equilibration hold time for ingrowth of Ac-228, and subsequent measurements of Ac-228 using gas proportional counting or liquid scintillation counting. As described above for the case of Ra-226, the form and solubility of radium in alkaline waste is very similar to strontium - present as an insoluble carbonate and highly partitioned to the solid phase. Because the parent isotope (Th-232) is also very insoluble, the concentrations of Ra-228 in HLW sludge can be effectively scaled based upon the age of the waste and the concentration of Th- 232 . Laboratory analysis of Th-232 by ICP-MS is a straightforward means of determining theTh-232 concentration. No back-decay adjustment of the Th-232 concentration is required, due to its extremely long half-life relative to the current age of the waste. As such, the current Th- 232 concentration is essentially equivalent to that at time zero. Knowing the Th-232 concentration, the Ra-228 concentration is calculated as a function of time using the following relationship:

$\mathrm{A}_{\mathrm{Ra}-228}(\mathrm{t})=\mathrm{A}_{\mathrm{Th}-232, \mathrm{t}=0} * \exp (-0.693 \mathrm{t} / 1.4 \mathrm{E}+10) *[1-\exp (-0.693 \mathrm{t} / 5.76)]$

where $A_{T h-232, t=0}$ is the Th-232 activity in the fresh waste (equivalent to the current activity), and $\mathbf{t}$ is the age of the waste in years. See Appendix K for an example of the scaling calculation. 
Ac-227 and Pa-231: Ac-227 and Pa-231 are produced through serial transformation of U-235. Their half-lives are 21.8 and 32800 years, respectively. The applicable decay sequence is: U-235 $\Rightarrow$ Th-231 $\Rightarrow$ Pa-231 $\Rightarrow$ Ac-227. Because of the long half-life of U-235 (7.0E+08 years), the ingrown Ac-227 and Pa-231 will persist millions of years into the future. Ac-227 is also the decay product of $\mathrm{Ra}-227$ produced by the $\mathrm{Ra}^{226}(\mathrm{n}, \gamma)$ activation reaction. However, since the quantity of Ra-226 in targets and fuel is small and most Ac-227 produced by activation of Ra-226 is transmuted to Ac-228 during irradiation (due to the high thermal neutron cross section of Ac-227, 900 barns), the majority of Ac-227 in aged HLW is expected to be that from decay of Pa-231. Similarly, although Pa-231 can also be produced through activation of $\mathrm{Pa}-230$, a source of $\mathrm{Pa}-230$ is not expected in typical SRS targets or fuel, so the majority of Pa-231 in aged HLW is expected to be that from serial transformation of U-235.

Laboratory analysis of Ac-227 is typically performed using chemical separations to remove the cesium (to increase the sensitivity), followed by high resolution gamma spectroscopy measurements. An alternative approach (to increase the sensitivity further) is to perform chemical separations to purify the thorium, measure the daughter product Th-227 via alpha spectrometry, and then quantify Ac-227 based on the Th227. In contrast, laboratory analysis of $\mathrm{Pa}-231$ is typically performed using chemical separations to purify the protactinium and subsequent $\mathrm{Pa}-231$ measurements via ICP-MS. Like other actinides, actinium and protactinium are expected to be very insoluble in alkaline waste and therefore highly partitioned to the solid phase, likely in the form of hydroxides and/or oxides. Because the parent radionuclide (U-235) is also very insoluble, the concentrations of Ac-227 and Pa-231 in HLW sludge can be scaled based upon the age of the waste and the concentration of U-235. Laboratory analysis of U-235 by ICP-MS is typically straightforward. No back-decay adjustment of the U-235 concentration is required, due to its extremely long half-life relative to the current age of the waste. (The current U-235 concentration is essentially equivalent to that at time zero). Knowing the U-235 concentration, the Ac-227 and Pa-231 concentrations are calculated as a function of time using the following relationships: $:^{33}$

$\mathrm{A}_{\mathrm{Ac}-227}(\mathrm{t})=\mathrm{A}_{\mathrm{U}-235, \mathrm{t}=0} * \exp (-0.693 \mathrm{t} / 7.04 \mathrm{E}+08) *[1-1.00066 \exp (-0.693 \mathrm{t} / 32800)+6.6 \mathrm{E}-04 \exp (-0.693 \mathrm{t} / 21.8)]$

and

$\mathrm{A}_{\mathrm{Pa}-231}(\mathrm{t})=\mathrm{A}_{\mathrm{U}-235, \mathrm{t}=0} * \exp (-0.693 \mathrm{t} / 7.04 \mathrm{E}+08) *[1-\exp (-0.693 \mathrm{t} / 32800)]$,

where $A_{\mathrm{U}-235, \mathrm{t}=0}$ is the $\mathrm{U}-235$ activity in the fresh waste (equivalent to the current activity), and $\mathbf{t}$ is the age of the waste in years. See Appendix L for examples of the Ac-227 and Pa-231 scaling calculations.

Th-229: Th-229 is the daughter of fissile radionuclide U-233. Since the half-lives of Th-229 and U-233 are 7300 and $1.59 \mathrm{E}+05$ years, respectively, the Th-229 grows-in over tens of thousands of years into the future, and then persists for hundreds of thousands of years more. Because U-233 is produced in special campaigns through the $\operatorname{Th}^{232}(\mathrm{n}, \gamma)$ activation reaction, significant concentrations of it will only be present in waste associated with those campaigns. Laboratory analysis of Th-229 is performed using chemical separations to purify the thorium, and subsequent measurement via alpha spectrometry. Like other actinides, thorium is very insoluble in alkaline waste and therefore highly partitioned to the solid phase, likely in the form of a hydroxide or oxide. Because uranium is also very insoluble, the concentration of Th-229 can be scaled based upon the age of the waste and the concentration of U-233. Laboratory analysis of U-233 is typically straightforward. No back-adjustment of the U-233 concentration is required, due to its long half-life relative to the current age of the waste. (The current U-233 concentration is essentially equivalent to that at time zero). Knowing the U-233 concentration, the Th229 concentration is calculated as a function of time using the following relationship:

$\mathrm{A}_{\mathrm{Th}-229}(\mathrm{t})=\mathrm{A}_{\mathrm{U}-233, \mathrm{t}=0} * \exp (-0.693 \mathrm{t} / 1.59 \mathrm{E}+05) *[1-\exp (-0.693 \mathrm{t} / 7300)]$, 
where $A_{U-233, t=0}$ is the $\mathrm{U}-233$ activity in fresh waste (equivalent to the current activity), and $\mathbf{t}$ is the age of the waste in years. See Appendix $M$ for an example of the scaling calculation.

Th-232: Th-232 is the naturally occurring actinide isotope that is irradiated in the reactor for the purpose of producing fissile U-233. With a half-life of $1.4 \mathrm{E}+10$ years, existing Th-232 will persist billions of years into the future. Because the frequency of Th-232/U-233 campaigns at SRS was low, significant quantities of Th-232 can be found in only a few select SRS HLW waste tanks. Laboratory analysis of Th232 is relatively simple utilizing ICP-MS measurements. As described above, thorium is very insoluble in alkaline waste and therefore highly partitioned to the solid phase, with the other actinides. Given that Th-232 presence and abundance is highly waste specific (and therefore highly variable), a simple means of scaling Th-232 is not available.

U-232, 233, 234, 235, 236, and 238: The sources of uranium isotopes are varied, depending on the campaign objectives, source material, and isotope. U-232 and U-233 are most associated with U-233 production from irradiation of Th-232 (see discussions of U-233 in Th-229 and Th-232 sections above). U-232 has multiple production paths, including those from the $\mathrm{U}^{233}(\mathrm{n}, 2 \mathrm{n}), \mathrm{Pa}^{233}(\mathrm{n}, 2 \mathrm{n})$, and $\mathrm{Pa}^{231}(\mathrm{n}, \gamma)$ activation reactions. U-233 can also be present as a decay product of Np-237 (Np-237 $\Rightarrow \mathrm{Pa}-233 \Rightarrow \mathrm{U}-$ 233). U-234, 235, and 238 are associated with depleted uranium targets irradiated to produce $\mathrm{Pu}-239$ through the $U^{238}(n, \gamma)$ activation reaction. They, along with $U-236$, are also associated with processing to recover U-235 from spent fuels. An additional source of U-234 is decay of Pu-238. With exception of U232, all of the uranium isotopes have half-lives greater than 100,000 years. Specifically, the half-lives are 70 years for $\mathrm{U}-232,1.6 \mathrm{E}+05$ years for $\mathrm{U}-233,2.5 \mathrm{E}+05$ years for $\mathrm{U}-234,7.0 \mathrm{E}+08$ years for $\mathrm{U}-235$, $2.3 \mathrm{E}+07$ years for $\mathrm{U}-236$, and $4.5 \mathrm{E}+09$ years for $\mathrm{U}-238$. Laboratory analyses of isotopes 233 through 238 are typically straightforward utilizing ICP-MS. In contrast, laboratory analysis of U-232 requires chemical separations to purify uranium, alpha spectrometry measurements to determine the U-232:U-238 ratio, and normalization based on ICP-MS measurements of U-238.

As stated before, uranium is very insoluble in alkaline waste and therefore highly partitioned to the solid phase. Given that most HLW tanks received inputs from multiple processing sources, a simple means of scaling the uranium isotopes is not available. However, if a HLW tank is known to have only received a single source of waste, it may be possible to develop uranium scaling factors based on the isotope specification and the age of the waste.

Np-237: Np-237 is the decay product of U-237 produced through various uranium neutron capture reactions $\left[\mathrm{U}^{236}(\mathrm{n}, \gamma), \mathrm{U}^{238}(\mathrm{n}, 2 \mathrm{n})\right.$, and multiple neutron capture by $\left.\mathrm{U}-235\right]$. Np-237 is also produced through decay of Am-241. Np-237 has a 2.1E+06 year half-life, so it will persist long into the future. Laboratory analysis of Np-237 is typically straightforward utilizing ICP-MS. Neptunium is normally insoluble in alkaline waste. However, under high oxidizing conditions, the solubility can increase as $\mathrm{Np}(\mathrm{IV})$ is oxidized to $\mathrm{Np}(\mathrm{V})$. Given that $\mathrm{Np}-237$ has multiple sources and potentially variable solubility, a simple scaling factor for $\mathrm{Np}-237$ is not available.

$\mathrm{Pu}-238,239,241$, and 242: As in the case of uranium, the sources of plutonium isotopes are varied, depending on the campaign objectives, source material, and isotope. $\mathrm{Pu}-238$ is most associated with $\mathrm{Pu}-$ 238 production from decay of $\mathrm{Np}-238$ generated through the $\mathrm{Np}^{237}(\mathrm{n}, \gamma)$ activation reaction. $\mathrm{Pu}-238$ is also produced through the decay of $\mathrm{Cm}-242$. In contrast, $\mathrm{Pu}-239,241$, and 242 are most associated with $\mathrm{Pu}-239$ production through irradiation of $\mathrm{U}-238\left(\mathrm{Pu}-239\right.$ is the daughter of $\mathrm{U}-239$ from the $\mathrm{U}^{238}(\mathrm{n}, \gamma)$ activation reaction, and $\mathrm{Pu}-241$ and 242 are produced through multiple neutron capture by $\mathrm{U}-238$ and $\mathrm{Pu}-$ 239). The half-lives of the plutonium isotopes are varied. Specifically, the half-lives are 88 years for Pu238, 2.4E +04 years for $\mathrm{Pu}-239,14$ years for $\mathrm{Pu}-241$, and 3.8E+05 years for Pu-242. Laboratory analyses for $\mathrm{Pu}-238$ and 241 typically require chemical separations to purify the plutonium, followed by alpha spectrometry measurements for $\mathrm{Pu}-238$ and liquid scintillation counting for $\mathrm{Pu}-241$. In contrast, 
laboratory analyses of $\mathrm{Pu}-239$ and $\mathrm{Pu}-242$ are typically straightforward utilizing ICP-MS. If higher sensitivities are required for $\mathrm{Pu}-242$, plutonium purification is typically performed prior to the ICP-MS measurements. Like the other actinides, plutonium is very insoluble in alkaline waste and therefore highly partitioned to the solid phase. Given that most HLW tanks received inputs from multiple processing sources, a simple means of scaling the plutonium isotopes is not available. However, if a HLW tank is known to have only received a single source of waste, it may be possible to develop plutonium scaling factors based on the isotope specification and the age of the waste.

Am-241, Am-243, Cm-242, Cm-243, and Cm-244: The chemistries of americium and curium are similar, leading to similar solubilities and similar solid-liquid phase partitioning behavior. As in the case of uranium and plutonium, the sources of americium and curium isotopes are varied, depending on the campaign objectives, source material, and isotope. Am-241 is daughter of the relatively short-lived $\mathrm{Pu}-$ 241 (14 year half-life), and as such, increases significantly over the first few decades of the waste storage. Am-243, Cm-242, Cm-243, and Cm-244 are produced through multiple neutron capture by U-238, Pu239 , and higher isotopes. $\mathrm{Cm}-242$ is also produced by the $\mathrm{Am}^{241}(\mathrm{n}, \gamma)$ activation reaction and through decay of Am-242m. The half-lives of the isotopes are 433 years for Am-241, 7400 years for Am-243, 0.45 years for $\mathrm{Cm}-242,29$ years for $\mathrm{Cm}-243$, and 18 years for $\mathrm{Cm}-244$. Because of the range of halflives, the isotopic distribution changes significantly during typical HLW storage periods. Laboratory analyses of the isotopes is typically performed utilizing chemical separations to purify the americium and curium, followed by high resolution gamma spectroscopy to quantify the Am-241, LEPS measurements to quantify the Am-243 and Cm-243, and alpha spectrometry to quantify the Cm-242 and Cm-244. Like the other actinides, americium and curium are very insoluble in waste and therefore highly partitioned to the solid phase. Given that the typical HLW contains americium and curium isotopes from a number of potential sources, a simple means of scaling the isotopes is not available. However, if a HLW tank is known to have only received a single source of waste, it may be possible to develop $\mathrm{Am} / \mathrm{Cm}$ scaling factors based on the isotope specification and the age of the waste.

A detailed assessment will be required to determine applicability of scaling factors for Hanford wastes and other wastes. The impacts of dissolution and separation processes will need to be evaluated in the context of the source material, radionuclide production paths, reactor conditions, waste receipt histories, waste chemistry, and waste mixing. Such an assessment will likely require integration of process history, process knowledge, technical bases, and systematically-obtained analytical data to reach conclusions regarding which constituents are scalable and which are not, to identify reference constituents that will provide the bases for the scaling determinations, and to understand the limitations and uncertainties associated with the scaling determinations. General information on applicable WTP radionuclides and potential scaling factor use is given in the WTP Data Specification Process report. ${ }^{34}$

A primary goal of this report is provide examples of constituents that have been scaled at SRS and to provide the rationale for doing so (or not doing so). It is hoped that this information will aid in developing a path forward for determining scaling factor applicability at Hanford and for developing Hanford-specific scaling methodologies. Clearly, the scaling factors used at SRS may or may not be applicable to other sites - that is something that will need to be determined through a detailed assessment of site-specific processes, conditions, and characteristics, as described above.

Use of scaling factors offers potential cost savings related to reducing analytical requirements. However, the value of the scaling factors goes well beyond cost. The ability to demonstrate consistency between scaled values and measured values provides added assurance of process understanding and added confidence in analytical results. In cases where analytical difficulties are encountered, the ability to scale a constituent can make the difference between meeting a reporting deadline and missing the deadline. The understanding that comes with developing potential scaling factors is also of value, particularly from the perspective of demonstrating waste characterization knowledge to customers, regulators, and 
stakeholders. Although a cost-benefit analysis will aid in placing a monetary value on the benefit of utilizing scaling factors, it should not be the sole basis for reaching a decision regarding scaling factor use. The ability to demonstrate characterization understanding and to have alternative characterization means available must also be considered.

\subsection{Potential Analytical Comparisons}

In the same manner that effective scaling factors can facilitate understanding of the isotope distributions, comparisons of analytical data generated by independent methods can facilitate understanding of data uncertainties and anomalies. Although independent analysis of every individual radionuclide is neither practical nor possible, several independent analyses are typically conducted during the normal course of normal analytical operations, and comparison of results from such analyses provides a tangible basis for gauging data quality.

The options for performing independent analyses are a function of the laboratory capabilities, the analytical procedures, and the range of analytes that a laboratory routinely performs. As the laboratory capabilities and range of analyses increases, the number of independent techniques available for comparisons will increase. Rather than attempting to address every potential analytical comparison, a select couple of examples will be presented that offer utility, simplicity, and practicality to most radionuclide analysis laboratories. It is hoped that these examples will provide an impetus for identifying and utilizing other analytical comparisons that meet the laboratory's specific needs. ${ }^{35,36}$

Comparison of gross analyses versus isotope-specific analyses: Screening measurements of total alpha and total beta activities are typically performed prior to isotopic analyses, to understand the potential dose associated with the sample and to develop an effective handling/processing strategy. Such measurements offer a means of checking the magnitude of the isotopic concentration measurements. Specifically, comparison of the total alpha concentration versus the sum of the primary expected alpha-emitters $(\mathrm{Pu}-$ 238, Am-241, and Cm-244, for example), and comparison of total beta concentration versus the sum of the primary beta-emitters (Sr-90, Y-90, Cs-137, etc.) provides simple bases for confirming the magnitudes of the concentrations.

Comparison of uranium analyses: Multiple analytical methods are available for measuring total elemental uranium and for measuring the individual uranium isotopes: ICP-MS, ICP-AES, atomic absorption, kinetic phosphorescence analysis, alpha spectrometry, and gamma spectroscopy. Because of the importance of understanding uranium, it is recommended that a comparison be performed between the total uranium concentration as determined by an elemental method and the sum of the isotope concentrations as determined by an isotope-specific method. At SRNL, a common comparison is the total uranium concentration determined by ICP-AES versus the sum of the isotopes as determined by ICP-MS.

Comparison of plutonium analyses: Alpha spectrometry is typically utilized to quantify the activity of $\mathrm{Pu}-238$ and the sum of the $\mathrm{Pu}-239$ and $\mathrm{Pu}-240$ activity. In contrast, ICP-MS is utilized to measure the mass of $\mathrm{Pu}-239$, and the mass of $\mathrm{Pu}-240$. Because of the importance of fissile $\mathrm{Pu}-239$, it is recommended that a comparison be performed between the total $\mathrm{Pu}-239$ and $\mathrm{Pu}-240$ activity as determined by alpha spectrometry and the individual activities of $\mathrm{Pu}-239$ and $\mathrm{Pu}-240$ as determined by ICP-MS (with mass converted to activity). 


\subsection{Conclusions}

1) A limited number of potential scaling factors are available for estimating radionuclide concentrations in SRS HLW, as determined through SRS process knowledge, analytical data, characterization experience, and characterization needs. Potential scaling factors are not available for many radionuclides, due to process variations, process complexities, decay considerations, and/or solubility issues. Thirteen of the forty-five WTP DQO radionuclides are ones that have been effectively scaled in SRS HLW. These thirteen radionuclides are: Ni-59, Zr-93, Nb-93m, Cd-113m, Sn-121m, Sn-126, Cs-135, Sm-151, Ra-226, Ra-228, Ac-227, Pa-231, and Th-229.

2) Not all scaling factors used at SRS will necessarily be effective for Hanford waste. Effective utilization of scaling factors requires understanding of the radionuclide generation reactions, radionuclide removal reactions, and waste characteristics, supported by adequate empirical data. As such, it is important to ensure understanding of the radionuclide production sources and waste chemistry before reaching a decision regarding scaling factor applicability. Because of the differences between SRS and Hanford waste types, processing, and blending, a detailed assessment will need to be performed to determine the scaling factor applicability for Hanford waste.

3) In almost every case, effective use of the scaling factors addressed in this report is limited to characterization of solid-phase waste material. For this reason, it is likely that use of potential scaling factors at WTP will primarily be applicable to characterization of the HLW streams.

\subsection{Recommendation}

Develop a technically sound path forward for determining the utility and applicability of radionuclide scaling factors specific to meeting WTP characterization needs. This entails:

- Identification of those radionuclides that are critical to WTP processing (are all of the 45 WTP DQO radionuclides truly critical to WTP processing?)

- Gathering of sufficient process knowledge to understand the potential ranges of concentrations and distributions of critical radionuclides as functions of the waste type

- Demonstration of consistency between process knowledge and analytical data, where applicable

- Identification of potential scaling methodologies applicable to characterizing critical radionuclides

- Determination and demonstration of critical radionuclide scaling effectiveness

- Development of a characterization program that utilizes a combination of process knowledge, analytical measurements, and scaling factors to best advantage, and identifies a hierarchy for accepting results based on the various methods

Since the radionuclide characterization needs for WTP processing may be significantly different than those for the other HLW operations purposes (safe storage, waste transfers, dose calculations, etc.), it is recommended that careful consideration be given when identifying the radionuclide characterization information needed to support WTP feed qualification. Although it is easy to choose a wide range of radionuclides for characterization, there is great benefit in choosing the radionuclides strategically, in a manner that ensures utility and practicality are of the utmost importance. Ultimately, a well thought-out radionuclide characterization program will result in significant savings and be much more conducive to long-term efficient operations. 


\subsection{References}

1

Arakali, A. V., D. L. Banning, P. A. Benson, and D. A. Greer, "Initial Data Quality Objectives for WTP Feed Acceptance Criteria," 24590-WTP-RPT-MGT-11-014, River Protection Project Waste Treatment Plant, May 2011.

Reboul, S. H., M. J. Cercy, E. P. Shine, and J. E. Young, “Task Technical and Quality Assurance Plan for Hanford Waste Treatment and Immobilization Plant (WTP) Feed Acceptance and Qualification Support," SRNL-RP-2013-00310, Savannah River National Laboratory, June 2013.

“Savannah River National Laboratory Technical Report Design Check Guidelines," WSRC-IM2002-00011, Rev. 2, Westinghouse Savannah River Company, August 2004.

Radiological Health Handbook, Department of Health, Education, and Welfare, 1970.

Baum, E. M., H. D. Knox, and T. R. Miller, Nuclides and Isotopes: Chart of the Nuclides, $16^{\text {th }}$ Edition, Knolls Atomic Power Laboratory, 2002.

Fellinger, T. L., N. E. Bibler, and J. R. Harbour, "Characterization of and Waste Acceptance Radionuclides to be Reported for DWPF Macro 2 (ESP 215 - ESP 221)," WSRC-RP-99-00436, Rev. 1, Westinghouse Savannah River Company, March 2004.

Bibler, N. E., D. P. DiPrete, and J. R. Harbour, "Determination of Reportable Radionuclides for DWPF Sludge Batch 2 (Macro Batch 3)," WSRC-TR-2002-00255, Westinghouse Savannah River Company, September 2002.

Bannochie, C. J. and N. E. Bibler, "Determination of Reportable Radionuclides for DWPF Sludge Batch 3 (Macrobatch 4)," WSRC-TR-2005-00157, Savannah River National Laboratory, May 2005.

9 Bannochie, C. J., N. E. Bibler, and D. P. DiPrete, "Determination of Reportable Radionuclides for DWPF Sludge Batch 4 (Macrobatch 5)," WSRC-STI-2008-00142, Savannah River National Laboratory, May 2008.

Bannochie, C. J., N. E. Bibler, and D. P. DiPrete, "Determination of Reportable Radionuclides for DWPF Sludge Batch 5 (Macrobatch 6)," SRNL-STI-2009-00821, Savannah River National Laboratory, February 2010.

Bannochie, C. J. and D. P. DiPrete, "Determination of Reportable Radionuclides for DWPF Sludge Batch 6 (Macrobatch 7),” SRNL-STI-2011-00189, Savannah River National Laboratory, May 2011.

Reboul, S. H., D. P. DiPrete, D. R. Click, and C. J. Bannochie, "Reportable Radionuclides in DWPF Sludge Batch 7a," SRNL-STI-2011-00702, Savannah River National Laboratory, December 2011.

Crawford, C. L. and D. P. DiPrete, "Determination of Reportable Radionuclides for DWPF Sludge Batch $7 b$ (Macrobatch 9)," SRNL-STI-2012-00294, Rev. 1, Savannah River National Laboratory, August 2013. 
Martino, C. J., D. J. McCabe, T. B. Edwards, and R. L. Nichols, “Analysis of Tank 28F Saltcake Core Samples FTF 456 - 467," WSRC-STI-2006-00151, Savannah River National Laboratory, February 2007.

Martino, C. J., D. J. McCabe, R. L. Nichols, and T. B. Edwards, "Analysis and Dissolution Testing of Tank 25F Saltcake Core Samples (FTF 504 - 513),” WSRC-STI-2007-00123, Savannah River National Laboratory, August 2007.

Bannochie, C. J., "Results for the First Quarter 2012 Tank 50 WAC Slurry Sample: Chemical and Radionuclide Contaminant Results," SRNL-STI-2012-00286, Rev. 1, Savannah River National Laboratory, July 2012.

Georgeton, G. K. and J. R. Hester, "Characterization of Radionuclides in HLW Sludge Based on Isotopic Distribution in Irradiated Assemblies," WSRC-TR-94-0562, Rev. 1, Westinghouse Savannah River Company, January 1995.

Reboul, S. H., M. S. Hay, K. E. Zeigler, and M. E. Stone, "Tank 12 Sludge Characterization and Aluminum Dissolution Demonstration," SRNL-STI-2009-00180, Savannah River National Laboratory, March 2009.

Reboul, S. H., "Chemical Differences Between Sludge Solids at the F and H Area Tank Farms," SRNL-STI-2012-00479, Savannah River National Laboratory, August 2012.

Murphy, C. E., et al., "Tritium in the Savannah River Site Environment," WSRC-RP-90-00424, Rev. 1, Westinghouse Savannah River Company, May 1990.

Fowler, J. R. and C. J. Coleman, “Carbon-14 in Sludge,” DPST-83-2001, Savannah River Laboratory, December 1983.

Bibler, N. E. and J. R. Fowler, "Technical Basis for Eliminating Carbon-14 as a Reportable Radionuclide in DWPF Glass,” WSRC-TR-2004-00629, Savannah River National Laboratory, December 2004.

Chandler, J. R., “Ni-59, Ni-63, and Nb-94 in DWPF Saltcrete,” DPST-82-236, E. I. du Pont de Nemours \& Company, January 1982.

Reboul, S. H., "Nickel-59, Cerium-144/Praseodymium-144, and Ra-226 in Salt Feed," SRNLL3100-2009-00189, Savannah River National Laboratory, September 2009.

Bibler, N. E., T. L. Fellinger, and D. T. Hobbs, "Technetium-99 Behavior in Savannah River Site High Level Waste Sludges During Waste Processing," WSRC-TR-2004-00196, Savannah River Technology Center, April 2004.

Hill, P. J., "Soluble Phase Selenium-79, Technetium-99, and Tin-126 Inventories," CBU-PIT2005-00127, Westinghouse Savannah River Company, May 2005.

England, T. R. and B. F. Rider. ENDF-349, Evaluation and Compilation of Fission Product Yields, LA-UR-3106, Los Alamos National Laboratory, 1994.

JAEA, "Nuclear Data Center," http://wwwndc.jaea.go.jp/, Japan Atomic Energy Agency, 2013. 
Reboul, S. H., "Conclusions and Path Forward for Sn-126 in Low Curie Salt," HLW-PRE-20020030, Westinghouse Savannah River Company, August 2002.

Tran, H. Q., “Supernatant Phase Iodine-129 Inventory,” CBU-PIT-2005-00050, Westinghouse Savannah River Company, February 2005.

1 Tran, H. Q., “Total Iodine-129 Curie Inventory Report,” CBU-PIT-2005-00033, Westinghouse Savannah River Company, February 2005.

Monier, J. A. and T. C. Evans, “Thoria Powder Specifications,” EM Specification 162, E. I. du Pont de Nemours \& Company, May 1968.

3 Hutchens, G. J., "Estimate of Actinide Concentration by Radioactive Decay," CBU-PIT-200500040, Westinghouse Savannah River Company, March 2005.

Arakali, A. V., J. Evans, K. H. Abel, A. A. Okemgbo, and J. L. Meehan, "WTP Data Specification Process," 24590-WTP-RPT-RT-02-004, River Protection Project Waste Treatment Plant, May 2003.

"Strategy and Methodology for Radioactive Waste Characterization," IAEA-TECDOC-1537, International Atomic Energy Agency, March 2007.

Hill, R. L. and R. L. Hobart, "Data Analysis and Radionuclide Scaling Factor for the B-Cell Waste Stream,” HNF-4904, B+W Hanford Company, September 1999. 


\section{Appendix A: The Ni-59/Ni-63 Concentration Ratio}

1) Determine if the ratio of the measured Ni-59 and Ni-63 concentrations is consistent with expectations

Example case: SRS DWPF Sludge Batch 7b (SB7b) characterization ${ }^{13}$

Assumption: For 0-60 year old waste, the Ni-59:Ni-63 activity ratio will be between 0.007 and 0.019 .

Analytical results: Ni-59 concentration $=2.57 \mu \mathrm{Ci} / \mathrm{g}$; Ni-63 concentration $=160 \mu \mathrm{Ci} / \mathrm{g}$

Ni-59:Ni-63 activity ratio based on measurements: $2.57 \div 160=0.016$

Conclusion: Analytical results are consistent with expectations and waste is decades old.

2) Calculate the anticipated Ni-59 concentration based on the measured Ni-63 concentration

Assumption: A reasonably conservative estimate of the current $\mathrm{Ni}-59$ concentration will be calculated using a Ni59:Ni-63 ratio of 0.019 (at the upper end of the anticipated range)

Example case: First quarter 2012 SRS Saltstone Tank 50 Sample characterization ${ }^{16}$

Analytical results: Ni-59 concentration is $<16.5 \mathrm{pCi} / \mathrm{mL}$; Ni-63 concentration is $<8.47 \mathrm{pCi} / \mathrm{mL}$

Estimate of Ni-59 concentration based on Ni-69: $(<8.47 \mathrm{pCi} / \mathrm{mL}) \times 0.019=<0.16 \mathrm{pCi} / \mathrm{mL}$

Conclusion: Reported upper limit for Ni-59 concentration can be reduced by two orders of magnitude.

3) Project the ratios of Ni-59:Ni-63 as the waste ages over the next 1000 years

Assumptions: a) Upper and lower bounds of ratios for currently existing waste are 0.019 and 0.007 , respectively; b) Ni-59 and Ni-63 concentrations will decay over time per the Ni-59 half-life of 7.6E +04 years and the Ni-63 half-life of 101 years.

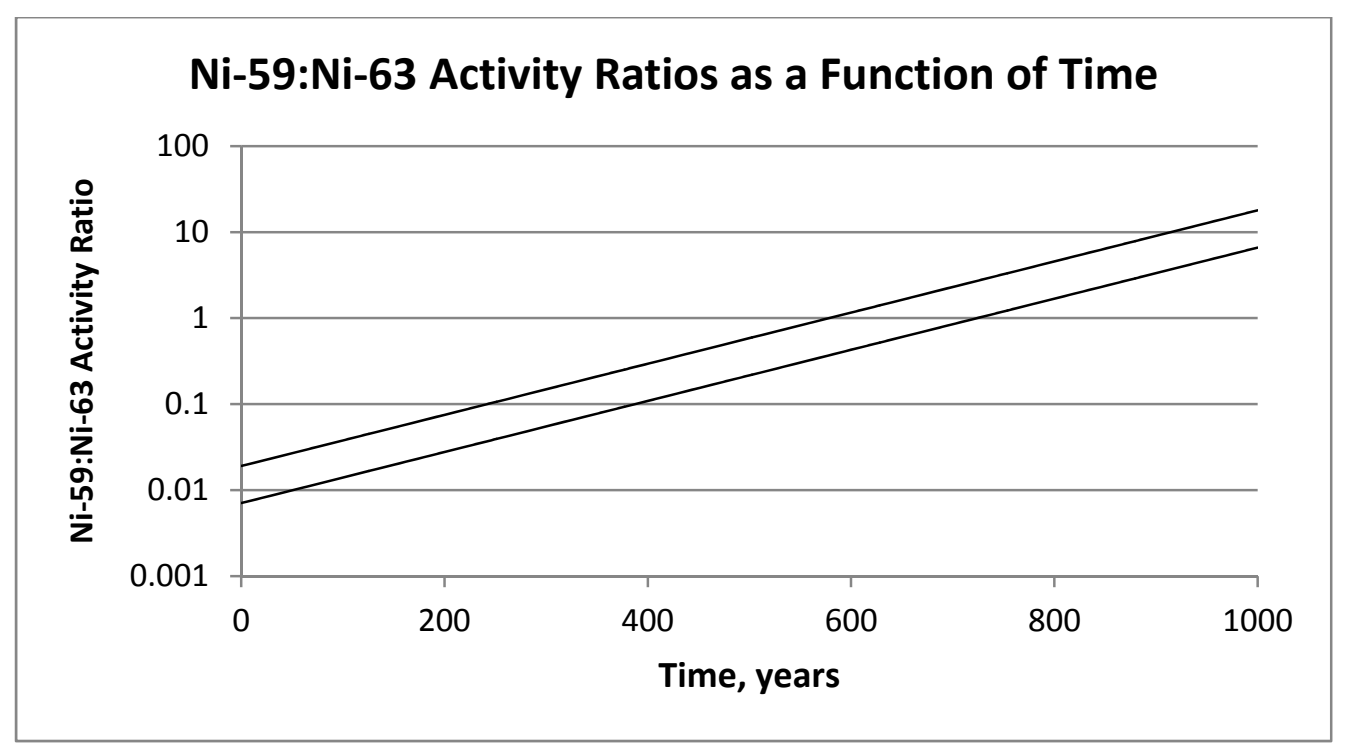

Conclusion: Ni-59:Ni-63activity ratios will increase four orders of magnitude over the next 1000 years. 


\section{Appendix B: Estimating the Age of the Waste}

The age of the waste can be estimated based on the Fission Yield Scaling Factor (FYSF) and the measured Sr-90 concentration. Rationale and criteria for the FYSF are described below, as documented by Bibler et al. in 2002. ${ }^{7}$ Note that for a given HLW sample, an average FYSF is determined based on a set of individual FYSFs applicable to the isotopes meeting the FYSF criteria. The individual FYSFs are computed from concentrations of the isotopes as measured by ICP-MS.

The FYSF is used to estimate concentrations of U-235 fission products that may be reportable but cannot be detected. In order to calculate the FYSF, as many as possible of the U-235 fission products were measured in the four sludge slurry samples. The fission products in SRS high level waste primarily result from the fission of U-235 used in the SRS reactors. The relative amounts (fission yields) of these products occur in a low and a high-mass fraction and their yields are well known from many studies. A compilation of these yields on an atom basis has been published [14].

The FYSF was determined using the fission yield and the measured concentrations in the sludge of those U-235 fission products that meet the following five criteria. These criteria are:

1. The isotopes had to have low solubilities in $\mathrm{NaOH}$ and thus occur predominantly in the sludge.

2. They had to have long half-ives and thus had not decayed significantly since the waste was generated.

3. The isotopes had to have low neutron cross-sections and thus were not transmuted in the SRS reactors during their operation.

4. The isotopes could not be formed in the reactors by neutron absorption.

5. Lastly, the isotopes had to have masses where interferences such as those from rare earth oxides formed in the Ar plasma did not create a problem.

Example case: SRS DWPF Sludge Batch 7b (SB7b) Characterization ${ }^{13}$

Analytical results: The measured Sr-90 concentration $=9.30 \mathrm{E}-03 \mathrm{wt} \%$

Assumption: For SB7b, the following fourteen fission products met the criteria identified above: Ru-101, Ru-102, Rh-103, Ru-104, La-139, Ce-140, Pr-141, Ce-142, Nd-143, Nd-144, Nd-145, Nd-146, Sm-147, and Sm-148.

For each isotope $\mathrm{i}, \mathrm{FYSF}_{\mathrm{i}}=\mathrm{wt} \% \mathrm{o}_{\mathrm{i}} \div\left(\mathrm{FY}_{\mathrm{i}} \mathrm{x} \mathrm{AM}_{\mathrm{i}}\right)$,

where $\mathrm{wt} \% \mathrm{o}_{\mathrm{i}}$ is the weight percent of isotope $\mathrm{i}$ (as measured by ICP-MS), $\mathrm{FY}_{\mathrm{i}}$ is the fission yield of isotope $\mathrm{i}$, and $\mathrm{AM}_{\mathrm{i}}$ is the atomic mass of isotope $\mathrm{i}$.

For SB7b, the average FYSF was 8.20E-05 (based on the fourteen calculated individual $\mathrm{FYSF}_{\mathrm{i}}$ values)

Calculations: Using the average FYSF, the estimated Sr-90 concentration at time zero was calculated:

a) $\mathrm{wt}_{\mathrm{Sr}-90, \mathrm{t}=0}=\mathrm{FYSF} * \mathrm{FY}_{\mathrm{Sr}-90} * \mathrm{AM}_{\mathrm{Sr}-90}=8.20 \mathrm{E}-05 * 5.80 * 90=0.0428$

The age of the $\mathrm{Sr}-90$ was then estimated based on the standard radiological decay relationship:

b) $\left.t=-t_{H} x \ln \left[C(t) / C_{0}\right)\right] \div 0.693=-28.8$ years $x \ln [0.00930 / 0.0428] \div 0.693 \approx 60$ years

Conclusion: The estimated age is consistent with the expectation that the waste is several decades old. Note that the uncertainty of the estimate is expected to be on the order of $\pm 20 \%$, due to the expected analytical uncertainties of the Sr-90 analysis and the ICP-MS measurements. 


\section{Appendix C: Estimating the Solid-Phase Zr-93 Concentration}

Estimate the Zr-93 concentration based on the Fission Yield Scaling Factor (FYSF)

Example case: SRS DWPF Sludge Batch 7b (SB7b) characterization ${ }^{13}$

Assumption: $\mathrm{FYSF}=\mathrm{wt}_{\mathrm{i}} \div\left(\mathrm{FY}_{\mathrm{i}} \times \mathrm{AM}_{\mathrm{i}}\right)=8.20 \mathrm{E}-05$ (see Appendix $\mathrm{B}$ for details of the FYSF)

Calculation: $\mathrm{wt}_{0 \mathrm{Zr}-93, \mathrm{t}=0}=\mathrm{FYSF} * \mathrm{FY}_{\mathrm{Zr}-93} * \mathrm{AM}_{\mathrm{Zr}-93}=8.20 \mathrm{E}-05 * 6.35 * 93=0.0484$

Note: Because the half-life of the $\mathrm{Zr}-93$ is so long (1.5E+06 years), its concentration will remain constant over many of thousands of years. As such, decay adjustment can be neglected over such periods.

Conclusion: The estimated $\mathrm{Zr}-93$ concentration is 2-3 times the concentration determined through laboratory analysis $(0.0184 \mathrm{wt} \%)$. This difference is attributed to a combination of two primary potential effects: a) the laboratory value may be biased low, due to incomplete digestion of the sample solids; and b) transmutation during irradiation was not taken into account in the calculation based on FYSF - as such, the value estimated from FYSF is expected to be an upper bounding value. Regardless of the source of the difference, the scaling technique provides a reasonable order of magnitude estimate of the $\mathrm{Zr}-93$ concentration and one that is conservative. 


\section{Appendix D: Estimating the Solid-Phase Nb-93m Concentration}

Estimate the $\mathrm{Nb}-93 \mathrm{~m}$ concentration based on in-growth from the $\mathrm{Zr}-93$

Example case: SRS DWPF Sludge Batch 7b (SB7b) characterization ${ }^{13}$

Assumption: Age of the waste $=53$ years

Analytical results: $\mathrm{Zr}-93$ concentration $=0.463 \mu \mathrm{Ci} / \mathrm{g}$

Note: Because the half-life of $\mathrm{Zr}-93$ is so long ( $1.5 \mathrm{E}+06$ years), its concentration at time zero is the same as it is now. Therefore, the measured result does not need to be back-decay adjusted.

Calculation:

$$
\begin{aligned}
\mathrm{A}_{\mathrm{Nb}-93 \mathrm{~m}}(\mathrm{t}) & =0.97 * \mathrm{~A}_{\mathrm{Zr}-93, \mathrm{t}=0} * \exp (-0.693 \mathrm{t} / 1.5 \mathrm{E}+06) *[1-\exp (-0.693 \mathrm{t} / 16.1)] \\
& =0.97 *(0.463 \mu \mathrm{Ci} / \mathrm{g}) * \exp (-0.693 * 53 / 1.5 \mathrm{E}+06) *[1-\exp (-0.693 * 53 / 16.1)] \\
& =0.40 \mu \mathrm{Ci} / \mathrm{g}
\end{aligned}
$$

A plot of the $\mathrm{Nb}-93 \mathrm{~m}$ concentration over the next 1000 years is given below.

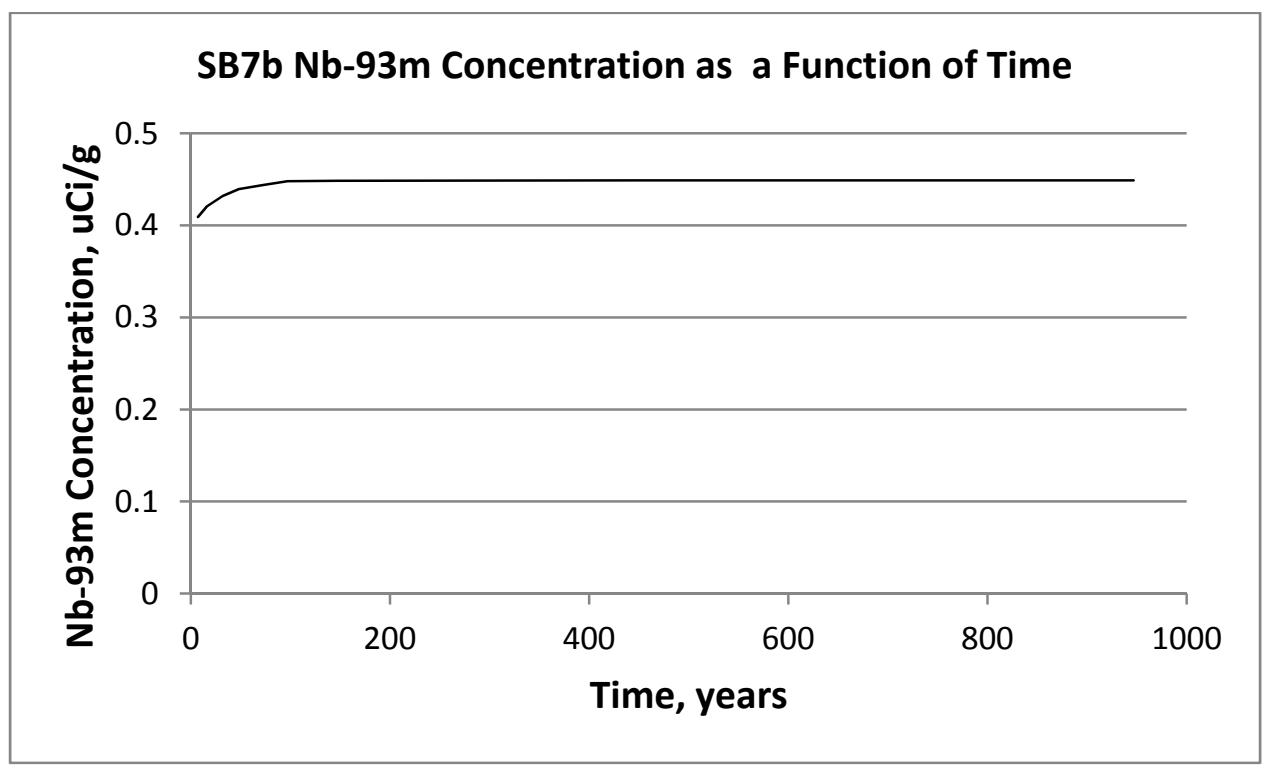

Conclusion: The $\mathrm{Nb}-93 \mathrm{~m}$ concentration will increase only slightly over the next 100 years and then remain constant for thousands of years. The relatively short in-growth period of the Nb-93m is indicative of the 16.1 year half-life. In contrast, the long-term concentration stability is due to the long half-life of the parent radionuclide ( $\mathrm{Zr}-93$ ). 


\section{Appendix E: Estimating the Solid-Phase Cd-113m Concentration}

Estimate the Cd-113m concentration based on the Fission Yield Scaling Factor (FYSF)

Example case: SRS DWPF Sludge Batch 7b (SB7b) characterization ${ }^{13}$

Assumption: $\mathrm{FYSF}=\mathrm{wt}^{0} \%_{\mathrm{i}} \div\left(\mathrm{FY}_{\mathrm{i}} \times \mathrm{AM}_{\mathrm{i}}\right)=8.20 \mathrm{E}-05$ (see Appendix B for details of the FYSF)

Calculation: $\mathrm{wt}_{\mathrm{C}} \%_{\mathrm{Cd}-113 \mathrm{~m}, \mathrm{t}=0}=\mathrm{FYSF} * \mathrm{FY}_{\mathrm{Cd}-113 \mathrm{~m}} * \mathrm{AM}_{\mathrm{Cd}-113 \mathrm{~m}}=8.20 \mathrm{E}-05 * 1.66 \mathrm{E}-04 * 113=1.54 \mathrm{E}-06$

Because the half-life of the Cd-113m is 14.1 years and the waste is decades old, a significant portion of the initial $\mathrm{Cd}-113 \mathrm{~m}(\mathrm{at} \mathrm{t}=0)$ has been lost to decay. A conservative estimate of the current concentration can be made by decay-adjusting the initial concentration for a period of time less than the actual age of the waste. For the purposes of this calculation, a decay period of 30 years will be assumed. This time period was chosen as being a reasonable underestimate of age based on the waste receipt history and the process knowledge.

Utilizing the standard relationship for radiological decay, the decay-corrected Cd-113m concentration is calculated as follows:

$\mathrm{C}_{\mathrm{Cd}-113 \mathrm{~m}}(\mathrm{t})=\mathrm{C}_{\mathrm{Cd}-113 \mathrm{~m}, \mathrm{t}=0} * \exp (-0.693 \mathrm{t} / 14.1)$, where $\mathrm{C}$ is concentration and $\mathrm{t}$ is time in years.

$\mathrm{C}_{\mathrm{Cd}-113 \mathrm{~m}}(\mathrm{t})=(1.54 \mathrm{E}-06 \mathrm{wt} \%) * \exp (-0.693 * 30 / 14.1)=3.5 \mathrm{E}-07 \mathrm{wt} \%$

A plot of the Cd-113m concentration over the next 1000 years is given below.

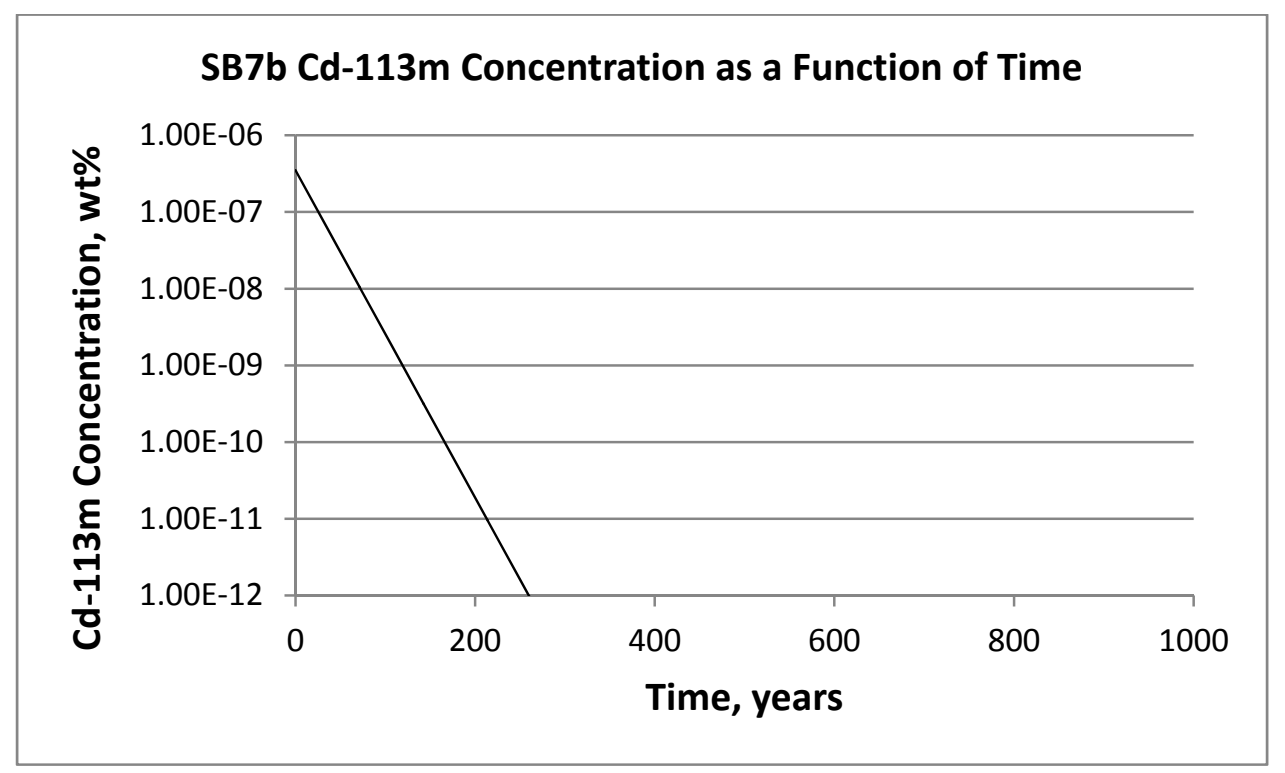

Conclusion: The Cd-113m concentration will decrease five orders of magnitude over the next 200 years and will be essentially gone a few hundred years later. 


\section{Appendix F: Estimating the Solid Phase Sn-121m Concentration}

Estimate the solid-phase Sn-121m concentration based on the solid-phase Sn-126 concentration and the liquid-phase $\underline{\text { Sn-121m:Sn-126 ratio }}$

Example case: SRS DWPF Sludge Batch $1 \mathrm{~b}(\mathrm{SB} 1 \mathrm{~b})$ characterization $^{6}$

Assumptions: Solid-phase Sn-126 concentration $=0.0142 \mu \mathrm{Ci} / \mathrm{g}$

Liquid-phase Sn-121m:Sn-126 activity ratio $=81$

Calculation:

Solid-phase Sn- $121 \mathrm{~m}$ concentration $=($ solid-phase Sn-126 concentration $) *($ Sn-121m:Sn-126 activity ratio $)$

$$
\begin{aligned}
& =(0.0142 \mu \mathrm{Ci} / \mathrm{g}) *(81 \mu \mathrm{Ci} \mathrm{Sn}-121 \text { per } \mu \mathrm{Ci} \mathrm{Sn}-126) \\
& =1.15 \mu \mathrm{Ci} / \mathrm{g}
\end{aligned}
$$

A plot of the Sn-121m concentration over the next 1000 years is given below.

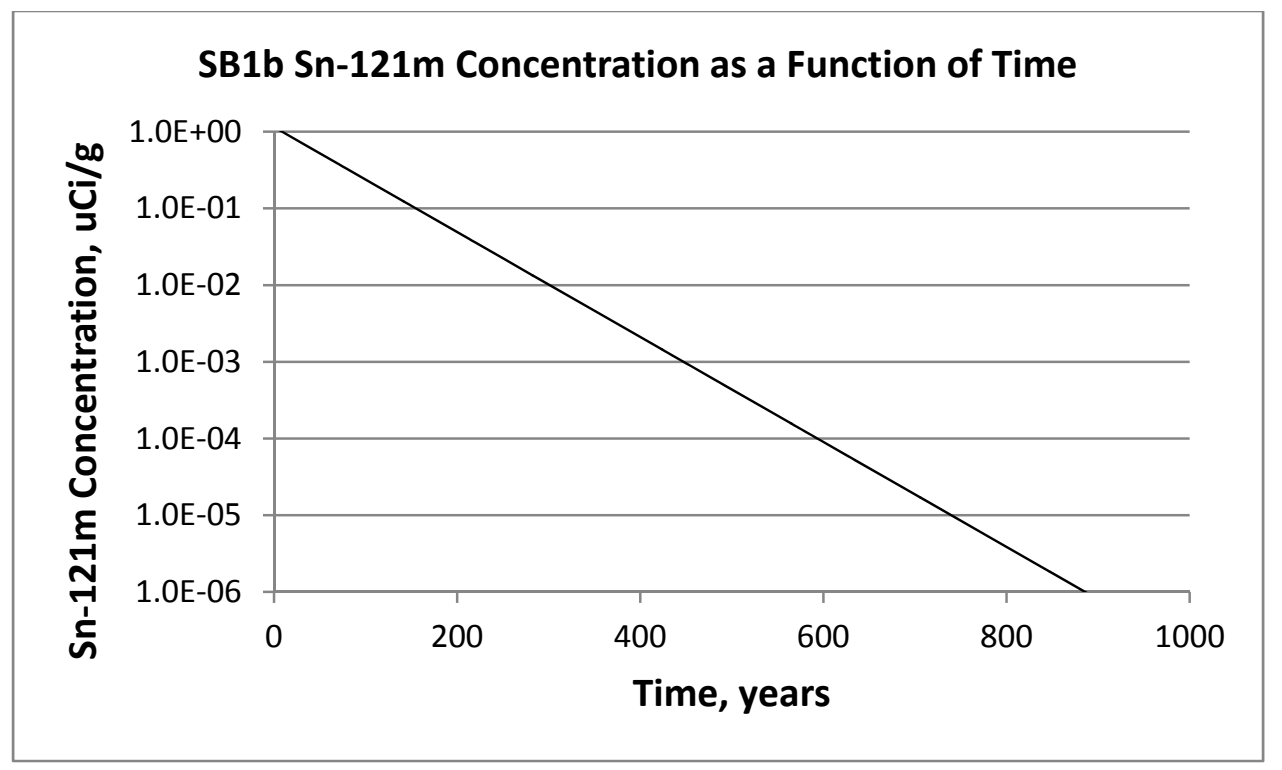

Conclusion: The Sn-121m concentration drops seven orders of magnitude over the next thousand years. 


\section{Appendix G: Estimating the Solid Phase Sn-126 Concentration}

Estimate the Sn-126 based on the Fission Yield Scaling Factor (FYSF)

Example case: SRS DWPF Sludge Batch 7b (SB7b) characterization ${ }^{13}$

Assumption: $\mathrm{FYSF}=\mathrm{wt} \%_{\mathrm{i}} \div\left(\mathrm{FY}_{\mathrm{i}} \times \mathrm{AM}_{\mathrm{i}}\right)=8.20 \mathrm{E}-05$ (see Appendix B for details of the FYSF)

Calculation: $\mathrm{wt}_{\mathrm{S} \mathrm{Sn}-126, \mathrm{t}=0}=\mathrm{FYSF} * \mathrm{FY}_{\mathrm{Sn}-126} * \mathrm{AM}_{\mathrm{Sn}-126}=8.20 \mathrm{E}-05 * 0.059 * 126=6.10 \mathrm{E}-04$

Note: Because the half-life of the Sn-126 is so long ( $2.3 \mathrm{E}+05$ years), its concentration will remain constant over many of thousands of years. As such, decay adjustment can be neglected over such periods.

Conclusion: The laboratory measurement for the solid-phase SB7b Sn-126 concentration gave a result of $<2.48 \mathrm{E}-03$ wt $\%$. In other words, the Sn-126 concentration was less than the minimum detection limit (MDL). In contrast, the concentration based on the FYSF is a factor of four lower than the MDL, and is still considered conservative, given that the estimate has not been adjusted for that portion of tin that is soluble. The ability to report a discrete Sn-126 concentration instead of an MDL is useful, as it provides a better basis for honing the concentration. 


\section{Appendix H: The Cs-135/Cs-137 Concentration Ratio}

1) Determine if the ratio of the measured Cs-135 and Cs- 137 concentrations is consistent with expectations

Example case: SRS DWPF Sludge Batch 7b (SB7b) characterization ${ }^{13}$

Assumptions: a) $\mathrm{FYSF}=\mathrm{wt}_{\mathrm{i}}{ }_{\mathrm{i}} \div\left(\mathrm{FY}_{\mathrm{i}} \times \mathrm{AM}_{\mathrm{i}}\right.$ ) (see Appendix B for details of the $\left.\mathrm{FYSF}\right)$; b) $\mathrm{FYSF}_{\mathrm{Cs}-135} \approx 0.10$ * $\mathrm{FYSF}_{\mathrm{Cs}-137}$ (due to transmutations reducing the $\mathrm{Xe}-135$ and Cs-135 concentrations); and c) the age of the waste is 53 years.

Calculations: At time zero, the mass concentration of Cs-135 $\approx 0.10 * \mathrm{FYSF}_{\mathrm{Cs}-137} * \mathrm{FY}_{135} * \mathrm{AM}_{135}$ $\approx 0.10 * \mathrm{FYSF}_{\mathrm{Cs}-137} * 6.54 * 135$,

and the mass concentration of Cs-137 $=\mathrm{FYSF}_{\mathrm{Cs}-137} * \mathrm{FY}_{\mathrm{Cs}-137} * \mathrm{AM}_{\mathrm{Cs}-137}=\mathrm{FYSF}_{\mathrm{Cs}-137} * 6.19 * 137$.

Thus, at time zero, the mass ratio of Cs-135:Cs-137 $\approx(0.10 * 6.54 * 135) \div(6.19 * 137)=0.104$

At $\mathrm{t}=53$ years, the mass ratio $=0.104 * \exp (-0.693 * 53 / 2.3 \mathrm{E}+06) / \exp (-0.693 * 53 / 30.1)=0.35$

Analytical results: Cs-135 concentration $=2.88 \mathrm{E}-04 \mathrm{wt} \%$; Cs- 137 concentration $=7.41 \mathrm{E}-04 \mathrm{wt} \%$

Ratio based on the analytical results: $(2.88 \mathrm{E}-04) \div(7.41 \mathrm{E}-04)=0.39$

Conclusion: The analytical results are consistent with the expectations - in this case, the difference is only about $10 \%$. Note that the uncertainty of the scaled value is a function of the accuracy of the age of the waste, and the uncertainty of the ratio based on analysis is a function of the analytical uncertainty.

2) Estimate the Cs-135 concentration based on the Cs-137 concentration and the age of the waste

Alternatively, the scaled Cs-135:Cs-137 ratio can be used to estimate the Cs-135 concentration based on the Cs-137 concentration. For this purpose, it is useful to apply an upper limit of the waste age, to introduce conservatism into the Cs-135 estimate. For SRS waste, a current reasonable upper limit is 60 years. At $\mathrm{t}=60$ years, the scaled mass ratio becomes 0.41 . For the SB7b case, application of this ratio to the lab-analyzed Cs-137 concentration (7.41E-04 $\mathrm{wt} \%$ ) leads to a Cs-135 concentration estimate of 3.0E- $04 \mathrm{wt} \%$. Because of the complexity of the Cs- 135 analysis method, there are times when estimating the Cs-135 concentration by the scaling factor may be the preferred option.

3) Project the ratios of Cs-135:Cs-137 as the waste ages over the next 1000 years

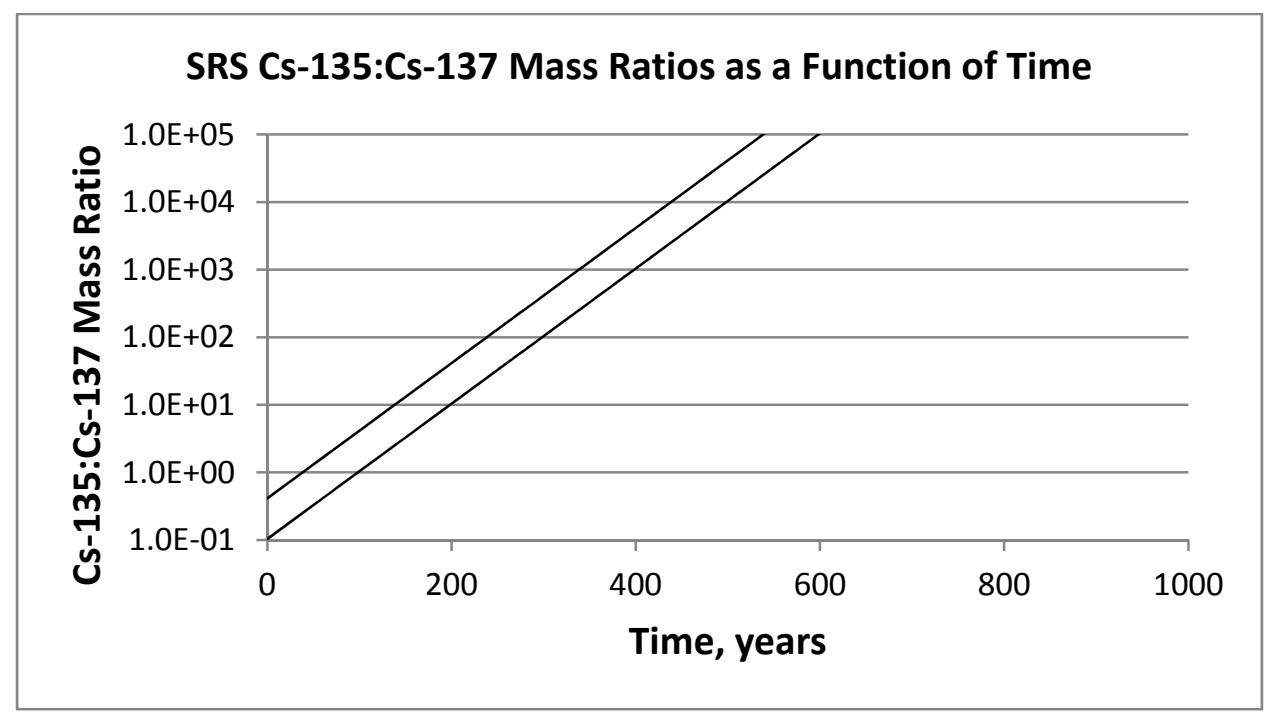

Conclusion: The ratio will increase ten orders of magnitude over the next thousand years. 


\section{Appendix I: Estimating the Solid Phase Sm-151 Concentration}

1) Estimate the Sm-151 concentration based on the Fission Yield Scaling Factor (FYSF) and the age of the waste

Example case: SRS DWPF Sludge Batch 7b (SB7b) characterization ${ }^{13}$

Assumptions: a) $\mathrm{FYSF}=\mathrm{wt}_{\mathrm{i}} \div\left(\mathrm{FY}_{\mathrm{i}} \times \mathrm{AM}_{\mathrm{i}}\right)=8.20 \mathrm{E}-05$ (see Appendix B for details of the $\mathrm{FYSF}$ ); b) $\mathrm{FYSF}_{\mathrm{Sm}-151} \approx$ 0.30 * FYSF (due to transmutations reducing the Sm-151 concentration); and c) the age of the waste is 53 years.

Calculation: $\mathrm{wt} \%_{\mathrm{Sm}-151, \mathrm{t}=0} \approx 0.30 * \mathrm{FYSF}^{*} \mathrm{FY}_{151} * \mathrm{AM}_{151}=0.30 * 8.20 \mathrm{E}-05 * 0.419 * 151=1.6 \mathrm{E}-03$

Because the half-life of the $\mathrm{Sm}-151$ is 90 years and the waste is decades old, a portion of the initial Sm-151 $(\mathrm{t}=0)$ has been lost to decay. A conservative estimate of the current concentration can be made by decay-adjusting the initial concentration for a period of time less than the actual age of the waste. For the purposes of this calculation, a decay period of 30 years will be assumed. This time period was chosen as being a reasonable underestimate of age based on the waste receipt history and the process knowledge.

Utilizing the standard relationship for radiological decay, the decay-corrected Sm-151 concentration is calculated as follows:

$\mathrm{C}_{\mathrm{Sm}-151}(\mathrm{t})=\mathrm{C}_{\mathrm{Sm}-151, \mathrm{t}=0} * \exp (-0.693 \mathrm{t} / 90)$, where $\mathrm{C}$ is the concentration and $\mathrm{t}$ is time in years.

$\mathrm{C}_{\mathrm{Sm}-151}(\mathrm{t})=(1.6 \mathrm{E}-03 \mathrm{wt} \%) * \exp (-0.693 * 30 / 90)=1.3 \mathrm{E}-03 \mathrm{wt} \%$

Analytical results: Sm-151 concentration $=9.4 \mathrm{E}-04 \mathrm{wt} \%$

Conclusion: As expected, the estimated $\mathrm{Sm}-151$ concentration is conservative, about $40 \%$ higher than the measured value.

As shown in the plot below, the Sm-151 concentration will drop three orders of magnitude over the next 1000 years.

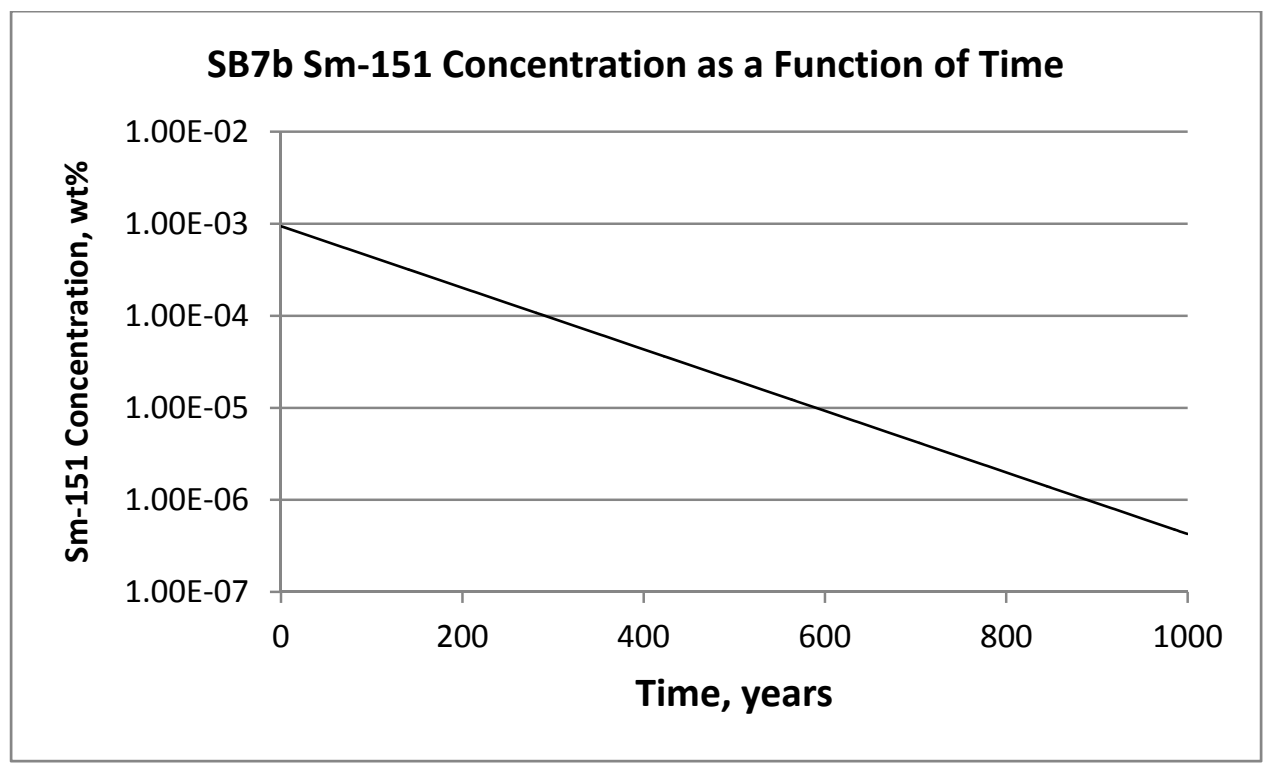




\section{Appendix J: Estimating the Solid Phase Ra-226 Concentration}

Estimate the Ra-226 concentration based on the concentrations of Th-230, U-234, and Pu-238 and the age of the waste

Example case: SRS DWPF Sludge Batch 7b (SB7b) characterization ${ }^{13}$

Assumptions: a) Age of the waste $=53$ years; b) concentration of Th-230 in Thoria $\left(\mathrm{ThO}_{2}\right)$ is 1 ppm by weight. ${ }^{32}$

Analytical results: Th-232 concentration $=1.08 \mathrm{wt} \%$; U-234 concentration $=6.49 \mathrm{E}-04 \mathrm{wt} \%$; Pu- 238 concentration $=8.32 \mathrm{E}-04 \mathrm{wt} \%$.

Calculations:

a) First, adjust the $\mathrm{Pu}-238$ concentration back to $\mathrm{t}=0$

$\mathrm{C}_{\mathrm{Pu}-238, \mathrm{t}=0}=\mathrm{C}_{\mathrm{Pu}-238, \mathrm{t}=53 \mathrm{yrs}} * \exp (0.693 * 53 / 87.7)=8.32 \mathrm{E}-04 \mathrm{wt} \% * 1.52=1.26 \mathrm{E}-03 \mathrm{wt} \%$

Note: Because the half-lives of Th-232 and U-234 are so long ( $1.4 \mathrm{E}+10$ and $2.46 \mathrm{E}+05$ years, respectively), their concentrations at time zero are the same as they are now. Therefore, the measured results for Th-232 and U-234 do not need to be back-decay adjusted.

b) Next, calculate the Th-230 based on the Th-232 concentration

$\mathrm{C}_{\mathrm{Th}-230}=1.0 \mathrm{E}-06 * \mathrm{C}_{\mathrm{Th}-232}=1.0 \mathrm{E}-06 * 1.08 \mathrm{wt} \%=1.08 \mathrm{E}-06 \mathrm{wt} \%$

c) Use a software program such as RadCalc 4.1 (Energy Solutions Federal Services, Inc.) to calculate the Ra-226 concentration as a function of time. For this particular calculation, enter the initial concentrations of Th-230, U-234, and $\mathrm{Pu}-238$ (at $\mathrm{t}=0$, as shown above), define a decay time of 53 years, and run the program.

As calculated by RadCalc, the current estimated Ra-226 concentration is $5.4 \mathrm{E}-10 \mathrm{wt} \%$. Future concentrations of Ra226 are simple to project by changing the in-growth times. A plot of the Ra-226 concentrations over the next 1000 years is given below.

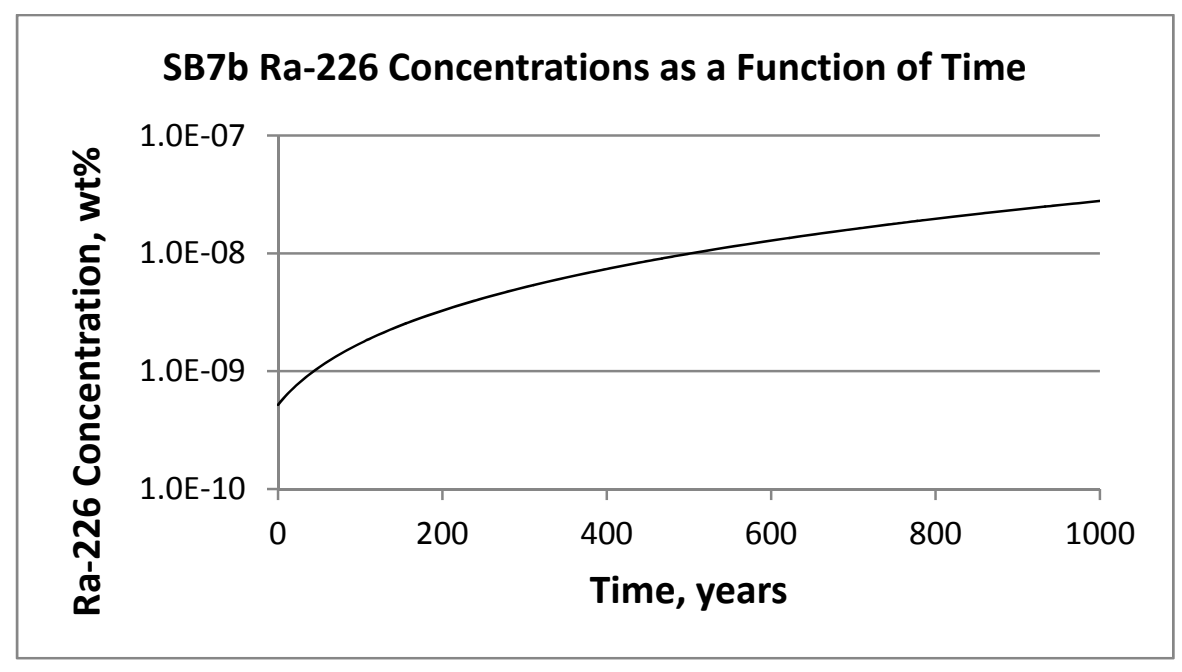

Conclusion: As shown in the plot, the Ra-226 concentration will increase two orders of magnitude over the next thousand years. 


\section{Appendix K: Estimating the Solid Phase Ra-228 Concentration}

Estimate the Ra-228 concentration based on the Th-232 concentration and the age of the waste

Example case: SRS DWPF Sludge Batch 7b (SB7b) characterization ${ }^{13}$

Assumption: Age of the waste $=53$ years

Analytical results: The Th- 232 concentration $=1.19 \mathrm{E}-03 \mu \mathrm{Ci} / \mathrm{g}$

\section{Calculation:}

Use the simple activity in-growth relationship below to estimate the current concentration of Ra-228. Note that the Th-232 concentration must be given in terms of activity (as opposed to mass) for the following relationship to apply.

$$
\begin{aligned}
\mathrm{A}_{\text {Ra-228 }}(\mathrm{t}) & =\mathrm{A}_{\text {Th-232,t=0 }} * \exp (-0.693 \mathrm{t} / 1.4 \mathrm{E}+10) *[1-\exp (-0.693 \mathrm{t} / 5.76)] \\
& =1.19 \mathrm{E}-03 \mu \mathrm{Ci} / \mathrm{g} * \exp (-0.693 * 53 / 1.4 \mathrm{E}+10) *[1-\exp (-0.693 * 53 / 5.76] \\
& =1.19 \mathrm{E}-03 \mu \mathrm{Ci} / \mathrm{g}
\end{aligned}
$$

Conclusions: Because of the short half-life of the Ra-228 relative to the waste age, the in-grown Ra-228 activity has reached secular equilibrium with that of the Th-232 activity. This Ra-228 activity will stay constant over many millions of years, due to the long half-life of the Th-232. 


\section{Appendix L: Estimating the Solid Phase Ac-227 and Pa-231 Concentrations}

Estimate the Ac-227 and Pa-231 concentrations based on the U-235 concentration and the age of the waste

Example case: SRS DWPF Sludge Batch 7b (SB7b) characterization ${ }^{13}$

Assumption: Age of the waste $=53$ years

Analytical results: The $\mathrm{U}-235$ concentration $=6.12 \mathrm{E}-04 \mu \mathrm{Ci} / \mathrm{g}$

\section{Calculation:}

Use the simple activity in-growth relationships below to estimate the current concentrations of Ac-227 and Pa-231. Note that the U-235 concentration must be given in terms of activity (as opposed to mass) for the following relationships to apply. Because the half-life of the $\mathrm{U}-235$ is so long $(7.04 \mathrm{E}+08$ years), its concentration at time zero is the same as it is now. Therefore, the measured result for $\mathrm{U}-235$ does not need to be decay-adjusted back to $\mathrm{t}=0$.

$$
\begin{aligned}
& \mathrm{A}_{\mathrm{Ac}-227}(\mathrm{t})=\mathrm{A}_{\mathrm{U}-235, \mathrm{t}=0} * \exp (-0.693 \mathrm{t} / 7.04 \mathrm{E}+08) *[1-\exp (-0.693 \mathrm{t} / 32800)+6.6 \mathrm{E}-04 \exp (-0.693 \mathrm{t} / 21.8)] \\
& \mathrm{A}_{\mathrm{Pa}-231}(\mathrm{t})=\mathrm{A}_{\mathrm{U}-235, \mathrm{t}=0} * \exp (-0.693 \mathrm{t} / 7.04 \mathrm{E}+08) *[1-\exp (-0.693 \mathrm{t} / 32800)]
\end{aligned}
$$

a) Calculate the Ac-227 concentration

$$
\begin{aligned}
\mathrm{A}_{\mathrm{Ac}-227}(\mathrm{t}) & =6.12 \mathrm{E}-04 \mu \mathrm{Ci} / \mathrm{g} * \exp (-0.693 * 53 / 7.04 \mathrm{E}+08) *[1-1.00066 \exp (-0.693 * 53 / 32800)+6.6 \mathrm{E}-04 \exp (-0.693 * 53 / 21.8)] \\
& =3.6 \mathrm{E}-07 \mu \mathrm{Ci} / \mathrm{g}
\end{aligned}
$$

b) Calculate the Pa-231 concentration

$$
\begin{aligned}
\mathrm{A}_{\mathrm{Pa}-231}(\mathrm{t}) & =6.12 \mathrm{E}-04 \mu \mathrm{Ci} / \mathrm{g} * \exp (-0.693 * 53 / 7.04 \mathrm{E}+08) *[1-\exp (-0.693 * 53 / 32800)] \\
& =6.8 \mathrm{E}-07 \mu \mathrm{Ci} / \mathrm{g}
\end{aligned}
$$

Concentrations over the next 1000 years are shown in the plot below, with the "top line" indicating the Pa-231 ingrowth curve and the "bottom line" indicating the Ac-227 in-growth curve. As depicted in the figure, the concentrations increase two orders of magnitude over the next thousand years. Due to the long half-life of Pa-231 (3.28E +04 years) and the even longer half-life of U-235 (7.04E +08 years), the concentrations of the daughter products will continue to increase over several hundreds of thousands of years.

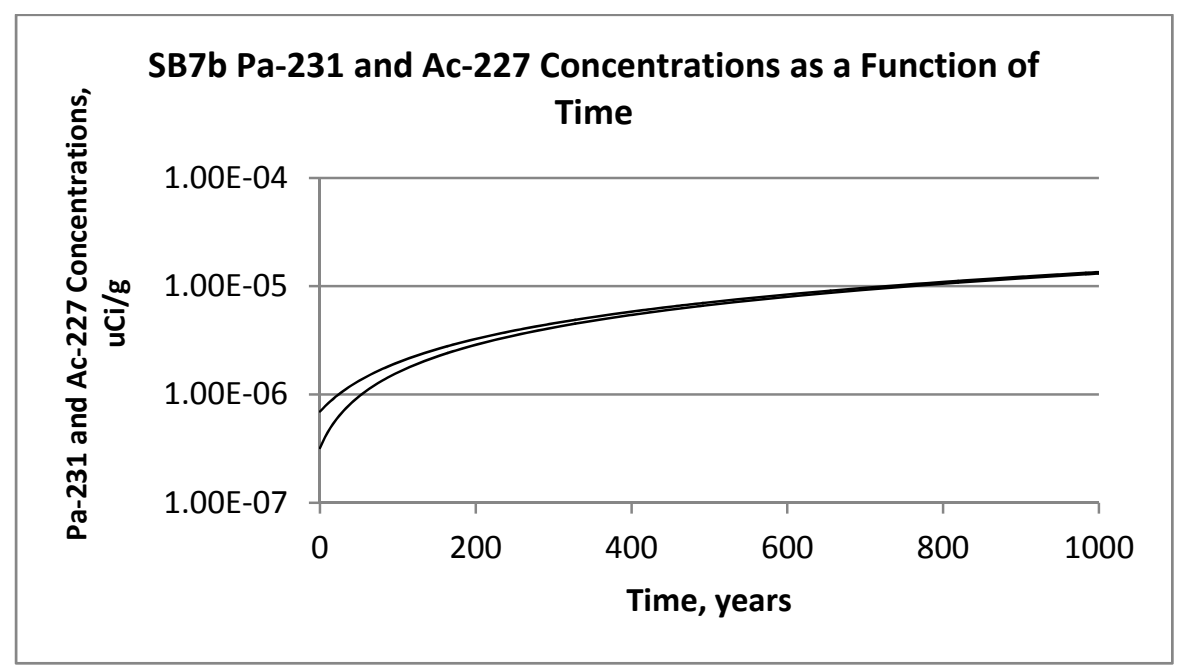




\section{Appendix M: Estimating the Solid Phase Th-229 Concentration}

Estimate the Th-229 concentration based on the U-233 concentration and the age of the waste

Example case: SRS DWPF Sludge Batch 7b (SB7b) characterization ${ }^{13}$

Assumption: Age of the waste $=53$ years

Analytical results: The $\mathrm{U}-233$ concentration $=4.22 \mathrm{E}-02 \mu \mathrm{Ci} / \mathrm{g}$

Calculation:

Use the simple activity in-growth relationship below to estimate the current concentrations of Th-229. Note that the U-233 concentration must be given in terms of activity (as opposed to mass) for the following relationship to apply. Because the half-life of the U-233 is so long (1.59E+05 years), its concentration at time zero is the same as it is now. Therefore, the measured result for $\mathrm{U}-233$ does not need to be decay-adjusted back to $\mathrm{t}=0$.

$$
\begin{aligned}
\mathrm{A}_{\mathrm{Th}-229}(\mathrm{t}) & =\mathrm{A}_{\mathrm{U}-233, \mathrm{t}=0} * \exp (-0.693 \mathrm{t} / 1.59 \mathrm{E}+05) *[1-\exp (-0.693 \mathrm{t} / 7300)] \\
& =4.22 \mathrm{E}-02 \mu \mathrm{Ci} / \mathrm{g} * \exp (-0.693 * 53 / 1.59 \mathrm{E}+05) *[1-\exp (-0.693 * 53 / 7300)] \\
& =2.1 \mathrm{E}-04 \mu \mathrm{Ci} / \mathrm{g}
\end{aligned}
$$

As shown in the plot below, the Th-229 concentration will increase an order of magnitude over the next thousand years. Over the next tens of thousands of years thereafter, the Th- 229 will continue to increase until decline of the U-233 (1.59E+05 year half-life) becomes significant.

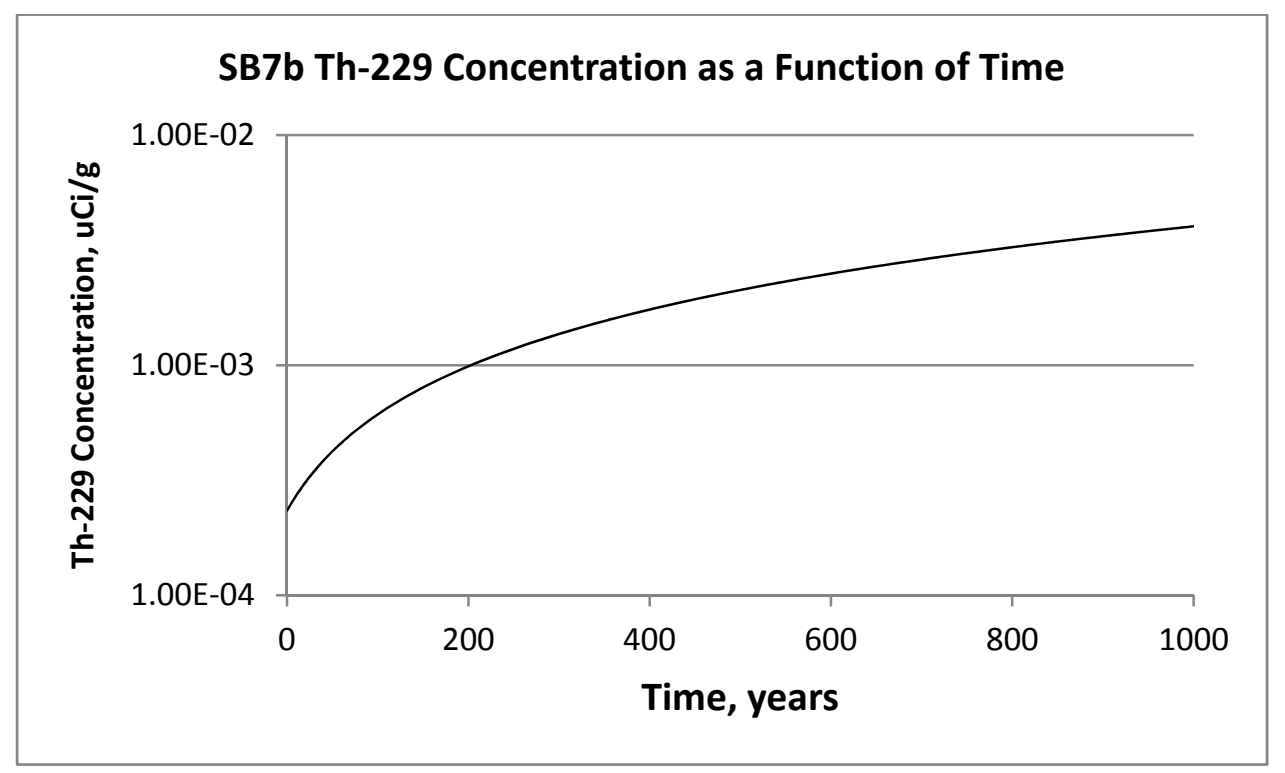




\section{Distribution:}

SRNL

D. J. Adamson, 999-W

T. B. Brown, 773-A

M. J. Cercy, 773-42A

D. R. Click, 999-W

T. B. Edwards, 999-W

S. D. Fink, 773-A

E. K. Hansen, 999-W

M. S. Hay, 773-42A

C. C. Herman, 773-A

E. N. Hoffman, 999-W

R. S. Lee, 773-41A

S. L. Marra, 773-A

D. K. Peeler, 999-W

J. R. Pelfrey, 773-42A

F. M. Pennebaker, 773-42A

M. R. Poirier, 773-42A

S. H. Reboul, 773-42A

M. E. Stone, 999-W

W. R. Wilmarth, 773-A

J. E. Young, 773-41A

Records Administration (EDWS)

SRR

J. M. Bricker, 704-30S

J. W. Ray, 704-S

K. H. Subramanian, 241-156H

DOE-SR

P. R. Jackson, 703-46A $\underline{\text { WTP }}$

A. V. Arakali

S. M. Barnes

P. A. Benson

G. M. Duncan

M. R. Hamlet

J. Markillie

J. L. Nelson

I. G. Papp

WRPS

S. T. Arm

T. W. Crawford

W. G. Ramsey

J. G. Reynolds

P. L. Rutland

S. A. Saunders

D. H. Shuford

M. G. Thien

L. E. Thompson

PNNL

R. D. Peterson

DOE-ORP

D. H. Alexander

S. L. Charboneau

J. A. Diediker

T. W. Fletcher

B. J. Harp

C. C. Harrington

A. A. Kruger

I. Wheeler

W. R. Wrzesinski 